\title{
Health and Wealth of Elderly Couples: Causality Tests Using Dynamic Panel Data Models*
}

\author{
Pierre-Carl Michaud and \\ RAND, Santa Monica, and IZA Bonn. \\ Arthur van Soest \\ Tilburg University, Netspar and RAND; avas@uvt.nl.
}

\begin{abstract}
A positive relationship between socio-economic status (SES) and health, the "health-wealth gradient", is repeatedly found in many industrialized countries. This study analyzes competing explanations for this gradient: causal effects from health to wealth (health causation) and causal effects from wealth to health (wealth or social causation). Using six biennial waves of couples aged 51-61 in 1992 from the U.S. Health and Retirement Study, we test for causality in panel data models incorporating unobserved heterogeneity and a lag structure supported by specification tests. In contrast to tests relying on models with only first order lags or without unobserved heterogeneity, these tests provide no evidence of causal wealth health effects. On the other hand, we find strong evidence of causal effects from both spouses' health on household wealth. We also find an effect of the husband's health on the wife's mental health, but no other effects from one spouse's health to health of the other spouse.
\end{abstract}

\section{Keywords}

health; inequality; aging; dynamic panel data models; causality

\section{Introduction}

One of the stylized facts in many industrialized countries is the positive association between health and wealth at the micro level, the "health-wealth gradient." Explaining this gradient has been a challenge for economists and other social scientists. Three types of explanations exist: causal effects from health to wealth, causal effects from wealth to health, and unobserved common factors that drive health and wealth in similar ways. It is important to distinguish these explanations to understand the sources of health inequalities and to design economic policy to improve welfare, health, and well-being.

Our paper differs from existing studies in that we use that dynamic linear panel data techniques to analyze the causal effects, allowing for unobserved heterogeneity and several lagged dependent variables. For this purpose, we use six waves (1992-2002) of the Health and

\footnotetext{
*We thank Jérome Adda, James Banks, Michael Hurd, Arie Kapteyn, Karl Scholz and James Smith for insightful discussions, seminar participants at RAND, Bristol, Tilburg, Maynooth, Tor Vergata, Laval and the 2004 Young Economist Meeting in Warsaw for comments and Manuel Arellano for making available the SNIV estimation code.

Corresponding address: 1776 Main Street, P.O. Box 2138, Santa Monica CA 90407-2138; michaud@ rand.org; fax: +1-310-574-3950.

JEL Codes: C33, D31, I12, J14.
} 
Retirement Study (HRS), a representative sample from the US cohort born between 1931 and 1941.

The main innovations are as follows. First, our dynamic panel data models do not only allows for unobserved heterogeneity, but also for a lag structure that is selected on the basis of specification tests and thus supported by the data. We explore the sensitivity of our causality test results to different sets of assumptions, particularly concerning the number of lags. A new finding is that the latter is quite important - specification tests show that two to three lags are needed to fit the data, and models with only one lag indeed lead to different (biased) conclusions. Thus, while existing studies use multiple data sources and many different specifications, an important methodological contribution of our study is to show that for a given data set, conclusions depend crucially on the specification.

Our main finding concerns the causal effects of wealth on health. Existing studies often find causal effects of household wealth on indexes of health. We show that this result disappears completely if we allow for unobserved heterogeneity and a lag structure supported by specification tests. In our preferred model specification, we find a strong causal effect of health on wealth, but no effect of wealth on health. Several robustness checks confirm this conclusion.

Our model considers couples, looking at household wealth and at health of both spouses. It thus also incorporates several explanations why health indexes of spouses are correlated, an issue which, to the best of our knowledge, is not addressed in a panel data context in the existing literature. In our preferred model with aggregate measures of health, we find no evidence of a causal effect of health of one spouse on health of the other spouse. When we disaggregate our measure of health, however, we find a causal effect of the husband's health on the wife's mental health two years later.

The paper is organized as follows. In Section 2, we discuss the health-wealth gradient and its potential sources, and existing studies on causal effects from health to wealth and wealth to health. In section 3 we describe the association between wealth and health and its time trend in our data. In section 4, the econometric framework is presented, with the identification, testing, and estimation strategies. Section 5 presents the results for the dynamic panel data models. In Section 6 we perform a sensitivity analysis and compare the results with those of simpler models. Section 7 concludes.

\section{The Health-Wealth Gradient and Its Sources}

In the United States, respondents to the 1984 wave of the Panel Survey of Income Dynamics (PSID) who reported excellent health had almost $75 \%$ higher median wealth than those who reported fair or poor health (Smith, 1999). Ten years later the ratio between median wealth of the same groups had grown to $274 \%$. The ratio in 1984 was largest for the age group 45-54, $176 \%$, which increased to $264 \%$ in 1994 . Although often less pronounced than in the U.S., a similar relation between socioeconomic status (SES) and health (the "health-SES gradient") is found in most industrialized countries with similar levels of health care technology and economic welfare (Wilkinson, 1996).

Understanding the sources of the health - wealth gradient is important to explain health inequalities and for policies aimed at improving welfare, health, and well-being (see, e.g., Deaton and Paxson, 1998). The gradient is also important because of the relation between health, retirement, and incentives of social security benefits and health insurance. Better health is positively associated with savings, labor force participation, and earnings, and negatively with the old age social security benefits replacement rate. Medicare availability at age 65 may explain the retirement peak in the US at that age, where social security incentives no longer apply (Rust and Phelan, 1997). Since the importance of public health insurance depends on 
health as well as SES, the health-SES relations are relevant for the debate on universal health care and the efficiency of proposed reforms.

Attempts to understand the different causal effects ("pathways") through which socioeconomic status and health affect each other have been numerous (see Smith, 1999 and Adler et al., 1994 for reviews). Causal pathways from health to wealth (also referred to as health causation) can be explained in a health production framework (cf. Grossman, 1972). Health and health expectations can affect productivity, hourly wages, and labor supply at the intensive and extensive margin, thus driving retirement decisions and the capacity to accumulate savings for retirement. Moreover, health directly affects expenditures, particularly in the US where about $20 \%$ of workers younger than 65 are not covered by health insurance and where copayments and additional health costs are substantial (Smith, 2005).

Pathways from wealth or, more generally, SES to health (SES or wealth causation) have been studied extensively in other social sciences (Adler et al., 1994) and economics (Adams et al., 2003; Adda, 2003; Hurd and Kapteyn, 2003; Meer et al., 2003; Smith, 2005). Potential SES health mechanisms are access to health care, health knowledge (cf. Kenkel, 1991), risk behavior (smoking and drinking; cf. Marmot, 2000), and wealth inequalities and the stress of being at the bottom of the distribution (Wilkinson, 1996; Marmot, 2000).

A third category of explanations for the gradient are early childhood factors. Several studies (Barker, 1997; Lindeboom et al., 2006; Ravelli et al., 1998) show that health is partly determined by health of the parents or health in early childhood, which will be related to the parents' SES and, due to the strong intergenerational correlation of SES, this can explain part of the health-SES gradient later in life. In our analysis of people aged 50 and over, such effects arise as permanent health shifts throughout the observation window, and we will model them as time persistent unobserved heterogeneity. Similar unobserved heterogeneity terms may drive household wealth, and the unobserved heterogeneity in household wealth and in health of both spouses can be correlated.

Earlier studies have aimed at disentangling these sources of the health-wealth gradient (Adams et al., 2003, Adda, 2003, Smith, 2005, Wu, 2003, and Meer et al., 2003). In these studies, noncausality is tested either without a rich lag structure or without controlling for unobserved heterogeneity, or both. As argued by Hausman (2003) and Mealli and Rubin (2003), this may bias the estimates and the test results, possibly explaining why the null of no causality is often rejected in both directions.

In this paper, we develop dynamic panel data models that make it possible to test for health and wealth causation, controlling for unobserved heterogeneity, using the econometric framework of Arellano and Bond (1991). Alonso-Borrego and Arellano (1999) emphasize that dynamic vector autoregressive panel data models offer an adequate framework for performing such tests. We apply the models to the HRS cohort of couples with at least one spouse born between 1931 and 1941 who are observed over six biennial waves from 1992 to 2002. We consider health for each spouse and wealth at the household level, as in Wu (2003). We consider two types of models - models without instantaneous effects of wealth on health and vice versa, in which no instruments are needed, and structural models with instantaneous links between health and wealth. In the latter models, we use the instruments of Smith (2005), Wu (2003), and Meer et al. (2003). In addition, we impose mean stationarity to increase efficiency of the estimates (avoiding potential weak instruments problems), following Blundell and Bond (1998). 


\section{Wealth and Health in the HRS cohort}

The Health and Retirement Study is a longitudinal survey of individuals aged 51-61 in 1992 in the US. Data were collected every two years and cover a wide range of aspects of the life of the 50+ population. In 1992, 12,652 interviews were conducted for a random sample of individuals born 1931-1941. Spouses of these individuals were included irrespective of their age. We use the public release file from the RAND Corporation that merged records from the six available waves (1992-2002). ${ }^{1}$ We selected all couples in the 1992 wave with complete information on the relevant variables. We retained observations with missing or bracket information on one or more components of wealth, using imputed values provided with the data set (see Hoynes et al., 1998). We observe couples until one spouse dies, until divorce or separation, or until at least one member of the household could not (or refused to) be interviewed. We do not analyze widows and widowers or divorced or separated spouses, since our models focus on the relation between wealth and health of both spouses.

Of the 4,160 households in 1992, 2,463 remained until 2002, implying an average annual attrition rate of about $5 \% .{ }^{2}$ For sample size, attrition rates, and some descriptive statistics, see See Appendix A ${ }^{3}$ Those who exit before the end of the panel are on average older, because of increasing mortality at older age. Attritors have slightly less education than respondents who remain in the panel for all six waves, while Blacks and Hispanics are more likely to exit than others.

\section{Wealth Data}

Liquid wealth consists of individual retirement accounts (IRAs), stocks, bonds, certificate deposits, T-bills/saving bonds, checking/saving accounts and other savings, net of financial debts (excluding mortgages). Non-liquid wealth includes the net value of the primary residence, other real estate, and vehicles. ${ }^{4}$ Wealth includes the value of life insurances and other annuities (in "other savings") but not the value of defined contribution pension plans. We will use log transformed wealth to reduce the effect of outliers. ${ }^{5}$

Table 1 describes the sample composition of wealth. It gives the median of each component conditional on ownership (and holding a positive amount) and the ownership rates for the 1992 and 2002 waves. In 1992, respondents held more than two thirds of their wealth in non-liquid assets, mainly the primary residence. The share of non-liquid assets in total wealth falls over the decade. Participation in stocks and IRAs is much more important in the US than in many other countries (Hurd, 2001). The median value of stocks and IRAs more than doubled over the 10 years, partly reflecting the high returns on these assets throughout this period.

\section{Health Variables}

Table 2 summarizes the health information for the 1992 and 2002 waves. In 1992, 16.7\% (23.8\%) of wives (husbands) had suffered from a condition that Smith (2005) labels as severe: cancer, heart condition, lung disease, or a stroke (or a combination of these). About one in every five respondents experienced their first severe health condition between the 1992 and the 2002 interview. In 2002, 81.3\% of husbands (79.9\% of wives) had experienced the onset of a mild health condition, mostly arthritis or high blood pressure. Emotional and psychological

\footnotetext{
${ }_{1}^{1}$ See http://www.rand.org/labor/aging/dataprod/.

2 From life-table figures, yearly death rates for this cohort vary from $0.5 \%$ to $2.6 \%$ over the decade considered (Berkeley Mortality Database: http://www.demog.berkeley.edu/wilmoth/mortality/).

${ }^{3}$ All appendices are available upon request from the authors.

${ }_{5}^{4} \mathrm{We}$ do not include business assets. These are nonzero for only few respondents but vary enormously over time for some respondents.

${ }^{5}$ To deal with zero wealth $(0.5-1 \%$ of the observations per wave) and negative wealth (2-3\% of the observations per wave), we use the following symmetric $\log$ transformation: $\log (y)=1(y \geq 0) \log (1+y)-1(y<0) \log (1-y)$; for positive values, this is virtually identical to $\log$ wealth. In the empirical analysis, we also compare with the hyperbolic transformation used by Adams et al. (2003).
} 
health problems are much more frequent for wives than for husbands, in line with the differences in CESD scores, combining eight yes/no indicators for mental and emotional health (e.g., whether respondents agree with the statement "everything is an effort"). The Body-Mass Index (BMI) increased more over time for wives than for husbands. The percentage having difficulties with activities of daily living (ADL) also increased over time and was always larger for wives than for husbands. We also use self-reported health, which conveys general information about health on top of specific onsets (cf., e.g., Hurd and Kapteyn 2003).

A "constructed health index" (CHI) combines the indicators presented in Table 2, using principal component (see Appendix B (available upon request) for its construction). The index is normalized such that it has mean 0 and variance 1 . Low values of the index refer to good health and high values to bad health. Most health variables contribute substantially to the CHI, with the highest score for self-reported health. To check the robustness of our findings, the empirical analysis will also consider some alternative health measures, e.g., not including selfreported health.

$\mathrm{CHI}$ of husband and wife are positively correlated. For example, $38 \%$ of wives with husbands in the best health quartile are in the best health quartile themselves, compared to only $16 \%$ of wives with husbands in the worst health quartile. ${ }^{6}$ This can be due to causal mechanisms (e.g. stress due to a health problem of the spouse), assortative mating, or common factors affecting both spouses' health in the same way (e.g. the environment, socio-economic position, or risk behavior).

\section{Association between Wealth and Health}

Table 3 reveals the health-wealth gradient in the 1992 and 2002 waves (cf. Smith, 1999,Table 1). It presents median household wealth by 1992 health quartile (using CHI as the health measure). In 1992, median household wealth of husbands in the best health quartile was more than twice as high as median household wealth of husbands in the worst health quartile. The same health differential is found between health quartiles of wives in 1992. The wealth differential increased further in 2002. These differences are of similar magnitude as those found by Hurd and Kapteyn (2003) and Smith (1999), who used self-reported general health instead of CHI. The large differences do not only appear in the tails of the distribution: even among the households with relatively healthy wives in the second quartile of the husbands' $\mathrm{CHI}$ distribution in 1992 , median wealth is 16.2 to $26.5 \%$ lower than in the top health quartile.

\section{Models and Tests}

\section{Model for the Evolution of Health and Wealth}

We develop a model for three outcome variables of couple $i$ in year $t: \boldsymbol{Y}_{i t}=\left(h_{i t}^{m}, h_{i t}^{f}, y_{i t}\right)^{\prime}$, where $h_{i t}^{m}$ and $h_{i t}^{f}$ are health of husband and wife, and $y_{i t}$ is log household wealth. As explained in section 1, a model explaining the evolution of wealth and health should have several features. First, it must capture immediate and lagged causal effects of wealth on health and of health on wealth. Second, it should allow for an effect of each spouse's health on health of the other spouse, as a possible explanation for the association between CHI's of both spouses. Third, it should take into account potentially correlated unobserved heterogeneity in health and wealth, leading to a permanent correlation between wealth and health during the observation window. We use the following panel data vector autoregressive model of order $P$ for $\mathbf{Y}_{\mathrm{it}}$, capturing all these features and allowing for the various explanations of the health - wealth gradient:

\footnotetext{
${ }^{6} \mathrm{~A}$ chi-square test rejects independence of CHI's of both spouses (p-value $<0.001$ ).
} 


$$
\boldsymbol{\Gamma} \boldsymbol{Y}_{i t}=\mathbf{A} \mathbf{x}_{i t}+\sum_{p=1}^{P} \Phi_{p} \boldsymbol{Y}_{i t-p}+\eta_{i}+\boldsymbol{\varepsilon}_{i t}
$$

The matrices $\boldsymbol{\Gamma}, \mathbf{A}$ and $\boldsymbol{\Phi}_{\mathrm{p}}, p=1, \ldots, P$ contain the parameters of the model. $\mathrm{x}_{i t}$ is a vector of time invariant and time varying characteristics (education, race, age, etc.). These can be correlated with a vector of time-invariant unobserved heterogeneity terms $\boldsymbol{\eta}_{i}$, capturing, e.g., genetic factors, early childhood events, etc. We will allow for correlation among the three components of $\boldsymbol{\eta}_{i}$ within a couple, as well as among the three transitory shocks in $\boldsymbol{\varepsilon}_{i t}$. The matrices $\boldsymbol{\Phi}_{1}, \ldots, \boldsymbol{\Phi}_{P}$ reflect causal links that take time to become effective. The coefficients of lagged wealth in the health equations reflect causal wealth - health effects, while those on lagged health in the wealth equation are health - wealth effects (Adda, 2003). Through the matrix $\Gamma$, we also allow for instantaneous causality. In our case, this is particularly relevant since observations are spaced by two years and causal effects may become effective faster than that.

To estimate the dynamic interactions between health and wealth consistently, it is crucial to incorporate a lag structure that is flexible enough to fit the data. In particular, the order of autoregression $P$ has to be large enough. Specification tests as in Arellano and Bond (1991) will be used to select a model that satisfies this.

Since individual effects can be correlated with the regressors in $\mathbf{x}_{i t}$, it is not possible to estimate the influence of time-invariant regressors or to disentangle the effects of age and a common time trend. We also do not explicitly incorporate risk behavior (smoking, drinking, body-mass index). Risk behavior may be one of the mechanisms through which SES affects health, though it can only explain part of the association (Lantz et al, 1998). Incorporating risk behavior variables would require a more structural approach than followed in the current paper.

We first consider the reduced form (RF) model from which instantaneous causality is eliminated and explain how to estimate this model and how to test for causal effects. We then turn to the structural form (SF) with instantaneous causality.

\section{Reduced-Form Vector Autoregressions}

Consider the reduced form Vector Autoregression of (1):

$$
\boldsymbol{Y}_{i t}=\mathbf{B} \mathbf{x}_{i t}+\sum_{p=1}^{P} \mathbf{C}_{p} \boldsymbol{Y}_{i t-p}+\eta_{i}^{*}+\boldsymbol{\varepsilon}_{i t}^{*}
$$

where $\mathbf{B}=\boldsymbol{\Gamma}^{-1} \mathbf{A}, \mathbf{C}_{p}=\boldsymbol{\Gamma}^{-1} \boldsymbol{\Phi}_{p}$ for $p=1, \ldots, P, \eta_{i}^{*}=\boldsymbol{\Gamma}^{-1} \eta_{i}$ and $\boldsymbol{\varepsilon}_{i t}^{*}=\boldsymbol{\Gamma}^{-1} \boldsymbol{\varepsilon}_{i t}$. The null hypothesis of no causal effects from wealth to husband's health can be written as

$$
H_{0}: E\left(h_{i, t+1}^{m} \mid \boldsymbol{Y}_{i}^{t}, \mathbf{x}_{i}^{t}, \eta_{i}^{*}\right)=E\left(h_{i, t+1}^{m} \mid \mathbf{h}_{i}^{t}, \mathbf{x}_{i}^{t}, \eta_{i}^{*}\right) \text { for } t=0, \ldots, T
$$

where $\mathbf{h}_{i t}=\left(h_{i t}^{m}, h_{i t}^{f}\right)^{\prime}, \boldsymbol{Y}_{i}^{t}=\left(\boldsymbol{Y}_{i 0}, \ldots, \boldsymbol{Y}_{i t}\right), \mathbf{h}_{i}^{t}=\left(\mathbf{h}_{i 0}, \ldots, \mathbf{h}_{i t}\right)$, and $\mathbf{x}_{i}^{t}=\left(\mathbf{x}_{i 0}, \ldots, \mathbf{x}_{i t}\right)$. In model (2), this takes the form

$$
H_{0}: \mathbf{C}_{1, m y}=\ldots=\mathbf{C}_{P, m y}=0
$$


where $\mathbf{C}_{p, m y}$ is the $m, y$ element of the matrix $\mathbf{C}_{p}$, the effect of p-periods lagged log wealth on the husband's health. Similarly, the null hypothesis of no causal effects from wealth to the wife's health takes the form:

$$
H_{0}: \mathbf{C}_{1, f y}=\ldots=\mathbf{C}_{P, f y}=0
$$

The null hypothesis of no causal effects from the husband's health to household wealth is given by

$$
H_{0}: E\left(y_{i t+1} \mid \boldsymbol{Y}_{i}^{t}, \mathbf{x}_{i}^{t}, \eta_{i}^{*}\right)=E\left(y_{i t+1} \mid y_{i}^{t}, h_{i}^{f t}, \mathbf{x}_{i}^{t}, \eta_{i}^{*}\right) \text { for } t=0, \ldots, T
$$

In model (2), this takes the form

$$
H_{0}: \mathbf{C}_{1, y m}=\ldots=\mathbf{C}_{P, y m}=0
$$

Similarly, the null hypothesis of no causal effects of the wife's health on household wealth takes the form

$$
H_{0}: \mathbf{C}_{1, y f}=\ldots=\mathbf{C}_{P, y f}=0 \text {. }
$$

Chamberlain (1984) labels (3) and (6) as "Granger non-causality on unobservables." Adams et al. (2003) look at individuals (in the older AHEAD cohort) instead of couples. Their tests are conditional on a covariates $\mathbf{x}_{i t}$ but not on unobserved heterogeneity $\eta_{i}^{*}$, and they only consider first order models. As Adams et al. (2003) emphasize, rejecting their null hypothesis leads to the conclusion that $y$ "Granger causes" $\mathbf{h}$ under the maintained hypothesis that there is no unobserved heterogeneity. They expect that this is not a major problem since they use a rich set of covariates $\mathbf{x}_{i t}$.

The reduced form model (2) can be estimated using GMM, based upon moments in first differences:

$$
E\left(\Delta \varepsilon_{i t}^{*} \mid Y_{i}^{t-2}, \mathbf{x}_{\mathbf{i}}^{\mathbf{t}}\right)=0 \text { for } t=2, \ldots, T
$$

First-differencing gets rid of the unobserved heterogeneity terms, but also introduces (negative) correlation between $\Delta \mathbf{Y}_{i t-1}=\left(\mathbf{Y}_{i t-1}-\mathbf{Y}_{i t-2}\right)$ and $\Delta \varepsilon_{i t}^{*}=\left(\boldsymbol{\varepsilon}_{i t}^{*}-\varepsilon_{i t-1}^{*}\right)$. This is why the history up to $t-2, \boldsymbol{Y}_{i}^{t-2}$, and not $\mathbf{Y}_{i, t-1}$, is used to construct moments (cf., e.g., Arellano and Bond, 1991). It implies that estimation (and testing for causal health-wealth or wealth-health effects) requires at least three observations per household.

If the health and wealth variables are close to non-stationary, then the instruments obtained from (9) may be weak since changes will be weakly correlated with past levels (see, e.g., Arellano, 2003). Blundell and Bond (1998) suggest solving this problem by assuming mean stationarity of errors and individual effects, leading to more moments and improving the efficiency of the estimator. Following Blundell and Bond (1998) and Arellano (2003), we impose the following additional moments: 


$$
E\left(\Delta Y_{i t-1}^{j}\left(\boldsymbol{Y}_{i t}-\mathbf{B} \mathbf{x}_{i t}-\sum_{p=1}^{P} \mathbf{C}_{p} \boldsymbol{Y}_{i t-p}\right)\right)=0 \text { for } t=3, \ldots, T ; j=1,2,3
$$

where $Y_{i t-1}^{j}, j=1,2,3$ are the components of the vector $\mathbf{Y}_{i t-1}$. These moments are valid under the following additional assumptions:

$$
E\left(\varepsilon_{i t}^{*} \eta_{i}^{*^{\prime}}\right) \text { does not depend on } t
$$

$$
E\left(\Delta \mathbf{x}_{i t} \eta_{i}^{j *}\right)=0, j=1,2,3
$$

The first of these implies that heterogeneity can be related to health or wealth shocks, but only in a way that does not vary over time. This assumption is not completely innocuous, since one may argue that the relation between permanent health endowments and health shocks vary with age. The assumption can be tested with a Sargan difference test on the additional overidentifying restrictions (and is not rejected in our final model).

The second assumption was already made - it is the basis for (9). It is justified if all correlation over time is picked up by the auto-regressive structure (the matrices $\boldsymbol{\Phi}_{p}, p=1, \ldots, P$ ) and the unobserved heterogeneity terms. Asumption (13) is innocuous in our case, since $\Delta \mathbf{x}_{i t}$ only contains time dummies (with age differences linear in time and other exogenous variables invariant over time). As Blundell and Bond (1998) emphasize, imposing mean stationarity or not is a trade-off between robustness and efficiency. Hence it is important to test the additional restrictions. We will do this using the increment in the Sargan test statistic (cf. Arellano and Bond, 1991).

\section{Structural Vector Autoregressions}

In the structural form (1), the hypothesis of non-causality implies restrictions on both the instantaneous effects in $\boldsymbol{\Gamma}$ and the lagged effects in $\boldsymbol{\Phi}_{p}$, similar to the restrictions in (4). For example, non-causality of wealth to husband's health implies:

$$
H_{0}: \boldsymbol{\Phi}_{1, m y}=, \ldots,=\boldsymbol{\Phi}_{P, m y}=\boldsymbol{\Gamma}_{m y}=0 .
$$

These restrictions are stronger than those for the RF model, since the RF parameters are linear combinations of the SF parameters that are restricted to zero under the null. Thus the test on the reduced form will not have power for some violations of non-causality in the structural form.

Without imposing additional identifying assumptions, we can estimate the RF parameters in (2) but not the SF parameters in $\boldsymbol{\Gamma}$ and $\boldsymbol{\Phi}_{p}$. Exclusion restrictions (i.e., instruments) are needed in order to identify the instantaneous causal mechanisms (cf. Hausman, 2003). Our instruments for health and wealth relate to shocks that do not have direct effects on the other outcome, following Smith (2005), Wu (2003), and Meer et al. (2003). As instruments for health changes, 
we use onsets of critical health conditions. Such onsets are quite frequent for our sample (Table 2). It seems plausible that they have no direct effect on wealth and thus can only affect wealth through the change in overall health that they induce. We use separate dummies for severe and mild onsets.

To instrument changes in wealth, we use inheritances. In each wave, about $5 \%$ of the households in the sample receive an inheritance; the median inheritance is $\$ 29,000$ and the mean is $\$ 64,100$ ). While the death of a family member might be correlated with the level of health due to genetic background or early childhood events etc., it seems reasonable to assume that it is not directly related to current health changes, making the inheritance an appropriate instrument for wealth changes. We use two instruments here: a dummy whether or not the couple received an inheritance in the last two years, and the size of that inheritance in dollars ( 0 if no inheritance was received).

To identify the instantaneous effect of health of one spouse on health of the other spouse, we also use the onsets of health conditions. Here we make the plausible assumption that such onsets have no direct effect on the other spouse other than through the constructed health index. We will test the overidentifying restrictions this implies.

As for the reduced form, we exploit the moments based upon mean stationarity of the errors and test these using the incremental Sargan test. Tests for "lagged" causality essentially remain the same as (3) and (6), except that they involve the matrices $\boldsymbol{\Phi}_{p}$ instead of $\mathbf{C}_{p}$. Tests for contemporaneous causation test whether elements of $\boldsymbol{\Gamma}$ are zero.

\section{Results}

To estimate the models we used the generalized method of moments (GMM; cf., e.g., Arellano and Bond, 1991). ${ }^{7}$ The additional mean stationarity moments (see Section 4 ) were not rejected by incremental Sargan tests. ${ }^{8}$ We include time dummies to pickup unobserved trends and, where necessary as indicated by specification tests rejecting invariance of coefficients over time, we also include interactions with a time trend. ${ }^{9}$

We estimate the three equations separately. We experimented with several lag structures and found that specifications with two lags (for wealth dynamics) and three lags (for health dynamics) were needed according to the usual specification tests (the Sargan test on overidentifying restrictions and the test on second order autocorrelation in the differenced residuals; see Arellano and Bond, 1991). ${ }^{10}$ The results for the selected models are presented in Tables 4, 5, and 6. Each table presents a reduced form equation without instantaneous effects of wealth on health etc., and a structural form equation in which the instruments proposed in Section 3 are used for identification.

\section{Effects of Health on Wealth}

Table 4 presents the results for equations explaining log household wealth. For the selected models, overidentifying restrictions are only mildly rejected at the $5 \%$ level ( $\mathrm{p}$-value $=0.04$ ). There is no evidence of second order serial correlation in the differenced errors, supporting the

\footnotetext{
${ }^{7}$ Since the cross-sectional dimension is quite large, we are not concerned about finite sample biases of two-step GMM, and use two-step GMM estimates constructing the optimal weighting matrix from first-step estimates.

${ }^{8}$ The test statistics are $13.87(\mathrm{df}=14 ; \mathrm{p}=0.459), 4.99(\mathrm{df}=10 ; \mathrm{p}=0.892)$ and $10.47(\mathrm{df}=10 ; \mathrm{p}=0.401)$ in the wealth, husband's health and wife's health equation respectively.

${ }^{9}$ In our fixed effects models, this may also be interpreted as an interaction with age.

${ }^{10}$ With one lag, the Sargan test statistic of the reduced-form model is $58.21(\mathrm{df}=36 ; \mathrm{p}=0.011)$ for the wealth equation. With two lags, it is $49.2(\mathrm{df}=30 ; \mathrm{p}=0.015)$ and $54.4(\mathrm{df}=30 ; \mathrm{p}=0.004)$ in the husband's and wife's health equation respectively. Thus these specifications are strongly rejected.
} 
hypothesis that the errors in levels are uncorrelated over time. The reduced form estimates and joint tests on coefficients of the lagged health imply significant negative effects of health of both spouses on $\log$ wealth.

The structural estimates provide no evidence for an immediate effect of husband's health on wealth, and the effects of the lagged husband's health indicator are similar to those in the RF equation. The joint significance of all husband's health variables remains. Current and lagged $\mathrm{CHI}$ of the wife are also jointly significant, but the immediate negative effect dominates the lagged effects. Thus, overall, we find strong evidence of causal effects of both spouses' health on household wealth. Moreover, the results of the structural model suggest an instantaneous effect for wives and a lagged effect for husbands. This may explain the difference with $\mathrm{Wu}$ (2003), who uses only two waves of the HRS and finds that the wealth of households tends to respond more to health events of the wife than to health events of the husband. A longer time span is needed to find the effect of the husband's health.

\section{Effects on Health of Wealth and Spouse's Health}

The results for the equation explaining the husband's health are presented in Table 5. Adding the second order lags and the interaction of lagged health with time was necessary to obtain a model that passes the tests on overidentifying restrictions and autocorrelation in the errors. The results provide no evidence whatsoever of an effect of wealth on husband's health. In both RF and SF, the wealth variables are jointly (and individually) insignificant. We also find no evidence of a causal effect of the wife's health on the husband's health. Similarly, Table 6 presents the results for the equations explaining the wife's health. They provide no evidence of causal effects from household wealth on the wife's health or from the husband's health on the wife's health.

\section{Unobserved Heterogeneity, Lag Structure, and Other Sensitivity Checks}

In this section we first investigate the nature of unobserved heterogeneity in the model of Section 5. Second, we compare the results of that model with those of simpler models, to see whether they really lead to different conclusions. Finally, we perform some robustness checks and we consider alternative definitions of health and wealth.

\section{Unobserved Heterogeneity}

The GMM residuals in each of the three equations are estimates of the sum of the error term and the unobserved heterogeneity term. Taking individual means over time gives an estimate of the unobserved heterogeneity term. These estimates can be used to estimate the covariance matrix of the unobserved heterogeneity terms, accounting for the small number of residuals (3, due to the required lags) used for each individual. Table 7 presents the estimated covariance matrix. For the wealth equation the unobserved heterogeneity term explains a substantial share of the total unexplained variance (1.12, about $82 \%$ of the total unexplained variance, 1.37). For the husband's and wife's health equations, the estimated shares are much smaller: $8.9 \%$ and $6.9 \%$, respectively. The correlations between the individual effects are also small.

Table 8 shows how the estimated individual effects (i.e., the household specific time means of the GMM residuals) in the three equations correlate with background variables measured at wave 1 . The relations are mostly as expected - keeping other background variables constant, fixed effects in the wealth equation are higher for husbands with more education, for households where both spouses are white compared to households with at least one black or Hispanic spouse, and for households where the wife is more active in financial planning. We find no relation with health behavior or survival status of parents in the wealth equation. For the fixed effects in the health equations, we find that health behaviors (both obesity and 
smoking) play a significant role. For wives, a negative correlation between the number of living parents and bad health is found as well as a positive correlation between manual occupation and health.

\section{Models with no Unobserved Heterogeneity or Fewer Lags}

We estimated some models that do not allow for unobserved heterogeneity and are more similar to the models analyzed by others. Tests for the hypothesis that wealth does not cause husband's and wife's health are presented in Table 9, based upon models that explain health of husband and wife from lagged health of husband and wife, lagged log wealth, and additional controls (demographics and past risk behavior). ${ }^{11}$. To increase comparability with Adams et al. (2003), we not only do this for CHI (first column) but also for the separate health variables used to construct CHI. We model (number of) ADLs, CESD score and self-reported general health as ordered probits, onsets as binary probits (for at least one mild or severe onset), and $\mathrm{CHI}$ as a continuous outcome. Standard errors are corrected for clustering of errors within households. We vary the number of lags of the dependent variable to check if allowing for more lags in levels leads to different conclusions.

In the first order models, the non-causality test is a joint test on the coefficient of $\left(y_{t-1}, y_{t-2}\right.$, $\left.y_{t-1} \times t\right)$. For husbands, the null is rejected in two out of six cases. For CHI, the null of no causality is rejected at the $10 \%$ level but not at the $5 \%$ level. For wives, the null of no causality from wealth to health is rejected in three out of six cases, including the case of CHI. This result differs from that in the complete model, where we found no significant effect of household wealth on the wife's health.

If more lags are added, the results provide much weaker evidence of causal wealth to health effects. Only for one of the husband's health indicators (CESD) and one of the wife's health indicators (severe onset) a significant effect is found. Thus allowing for a richer lag structure makes a substantial difference. ${ }^{12}$

Table 9 also presents tests for causal effects of the wife's health on the husband's health and vice versa (controlling for wealth etc.). Non-causality from the wife's health to the husband's health implies that coefficients for $\left(h_{t-1}^{f}, h_{t-2}^{f}\right.$ and $\left.h_{t-1}^{f} \times t\right)$ are all zero. First-order models suggest causality: In four out of six cases, a significant (and positive) effect of the wife's health on the husband's health is found and the effect of the husband's health on the wife's health is significantly positive in three cases. The significance levels of the effects on the spouse's mental health (CESD scores) are the highest. The results for CHI would suggest causal effects in both directions. With the higher order models, the only significant effect is an effect of husband's health on the wife's mental health (the CESD score). Interestingly, this effect does not disappear if we estimate a dynamic FE model for the wife's CESD index. This suggests a genuine causal effect of the husband's health on the wife's mental health. In models for the aggregated $\mathrm{CHI}$ health measure, this effect remains undetected since it gets swamped with the insignificant effects for other health dimensions.

Comparing the results for $\mathrm{CHI}$ with those in Tables 5 and 6 thus suggests that incorporating an appropriate lag structure makes the largest difference. Once this is done, controlling for fixed effects in the CHI models does not change the conclusions about causality. This is in line with the conclusion from Table 7 that unobserved heterogeneity terms in the health equations

\footnotetext{
${ }^{11}$ The regression results are in Appendix $\mathrm{C}$ (available upon request)

12 To check if unobserved heterogeneity plays a role in these last two cases, we also estimated the dynamic FE models with specifications as in Tables 5 and 6 for the husbands' CESD index and the wives' onset of a severe condition as the dependent variable. None of the effects remain significant at any conventional level, implying that the two rejections of no causality in models with three lags in Table 9 can be ascribed to not controlling for unobserved heterogeneity.
} 
are small. For the wealth equation, all models lead to the same conclusion - there are significant causal effects of both spouses' health indexes on household wealth.

\section{Other Robustness Checks}

A potential concern with our GMM estimates is finite sample bias due to weak instruments. Alonso-Borrego and Arellano (1999) suggest several alternative estimators that avoid the GMM bias due to weak instruments. We computed Symmetrically Normalized IV (SNIV) estimates, which have similar properties as LIML but are easier to compute. See Appendix D (available upon request), Table D.1, for the RF estimates. The estimation results for our favorite specification are similar to the results presented in Tables 4, 5 and 6 . Moreover, the causality tests give the same conclusions - the null of no causality is not rejected for wealth to health (p-values 0.948 for husbands and 0.204 for wives in the RF model) or from the wife's to the husband's health (p-value 0.553 ) or vice versa (p-value 0.932 ), but no causality from husband's or wife's health to household wealth is strongly rejected (p-values $<0.001$ and 0.002 ). The similarity of GMM and SNIV estimates suggests that we do not have a weak instruments problem.

Another robustness check concerns the log transformation of wealth, which may be seen as treating negative wealth values in a somewhat ad hoc manner. An alternative is the hyperbolic transformation of Adams et al. (2003). Again, we find essentially the same results - no causality from health to wealth is firmly rejected (p-values $<0.001$ for husband's and wife's health), but neither no causality from wealth to health (p-values 0.131 for husband's health and 0.301 for the wife's health), nor no causality from the wife's health on the husband's health (p-value 0.647) or vice versa (p-value 0.721) can be rejected. See Appendix D, Table D.2.

Finally, there is some concern whether our results are affected by selective attrition. Mortality is a source of attrition and is also related to health, making it unlikely that attrition is random. Following Nijman and Verbeek (1996), we compared the estimation results based upon balanced and unbalanced panels. If there is no attrition bias, both estimators have the same probability limit and their difference is expected to be small. On the other hand, if attrition is selective, both estimators are inconsistent with different probability limits, and they can be expected to give different results. Nijman and Verbeek (1996) use this intuition to construct a Hausman type test based upon the difference in the estimates and show that this test has more power than other, added-regressors type, tests.

In this paper we are primarily interested in whether attrition affects our conclusions about causality. We therefore compare the causality test outcomes for the balanced and unbalanced panels. the results are the same, suggesting that selective attrition does not drive the outcomes of the tests. For example wealth does not Granger cause husband's or wife's health in the balanced sample using reduced-form models ( $\mathrm{p}$-value $=0.642$ and 0.623 respectively compared to 0.713 and 0.691 with all observations).

This does not mean that selective attrition has no effect on the parameter estimates. As shown in Table D.3 in Appendix D, we reject the null that attrition is random for log wealth and husband's health equation but not for the wife's health. A more structural framework to account for the relations between attrition, wealth and health is needed to address the issue more satisfactorily. But this requires a very different approach which is beyond the goals of the current paper.

\section{Disaggregation}

Using the CHI incorporating all features of health, we found clear evidence of causal effects of both the husband's and the wife's health on household wealth. We estimated a similar 
dynamic panel data model using separate indicators for physical and mental health (Appendix E (available upon request), Table E.1). The physical health index combines all onsets except depression and ADL's, the mental health index combines the CESD score with the onset of depression. We found evidence of causal effects on household wealth of the husband's physical health and the wife's physical and mental health, but not of the husband's mental health. The effect of the wife's mental health is instantaneous, while the effect of the husband's physical health is not, in line with the difference between husbands and wives found earlier (Table 4). The stronger wealth effect of the wife's mental health status than of the husband's status is in line with Wu's (2003) argument that household expenditures increase if the wife can no longer perform tasks such as cooking and cleaning. The stronger effect of the husband's physical health might relate to his role as breadwinner. A model that simultaneously considers labor force participation and earnings would be needed to investigate this further. This would be an interesting direction for future research.

An explanation for the strong effects of mental health may be the lack of insurance coverage for mental health problems. Since their coverage by Medicare and Medicaid is limited, employer-provided or other additional insurance coverage is necessary to protect against mental disease onsets (Adams et al., 2003). To investigate this, we disaggregated the sample by health insurance coverage status, estimating separate models for couples where none had insurance coverage in their first wave and couples where both had coverage. We found that rejection of non-causality from health to wealth is more frequent for couples who lack health insurance (Table E. 2 in Appendix E). Immediate effects of mental health problems are stronger among non-insured couples. This suggests that health expenditure is an important channel for the effect of health on wealth in this age group, in particular for the uninsured. More research is needed to analyze this conjecture.

\section{Conclusion}

This paper uses dynamic panel data models to test for causal effects of health on socioeconomic status and vice versa for elderly couples in the US. The two main differences with earlier approaches is that this allows to control for unobserved heterogeneity and to select an appropriate lag structure using specification tests. Six biennial waves of couples in the HRS were used, following the 1931-1941 birth cohort from 1992 until 2002.

Our dynamic panel data model based tests provide clear evidence of causal effects from health to wealth, but no evidence of causal effects from wealth to either the husband's or the wife's health, or from one spouse's health on the health of the other spouse. Sensitivity analysis shows that simpler models without unobserved heterogeneity or with too few lags give biased results - they suggest causal effects of wealth on the health of both spouses. The covariance structure of the residuals suggests that unobserved heterogeneity in wealth plays a more important role than in both husband's and wife's health (where state dependence can explain almost all correlation over time).

Disaggregating health into mental and physical health show that mental health is more important for wives while only physical health matters for husbands. While the mental health effects are instantaneous, the physical health effects take more time and are visible only in the next wave (two years later). Insurance coverage also appears to play a role here: it is mainly if wives without employer-provided insurance experience an onset of mental conditions that household assets decline.

The fact that we find no causal links from wealth to health for the age groups considered does not mean that such a causal link never operated earlier in life - we only consider households with one or both spouses in their fifties. It would be interesting to apply the same approach to 
younger households. It would also be interesting to look at different countries, and see whether the institutional setting makes a difference (Deaton, 2003; Hurd and Kapteyn, 2003).

Further research could also explicitly incorporate the role of labor force participation and earnings. The respondents in the HRS cohort that we consider are typically at work in the first wave and have retired before the last wave. One of the potential channels of health-wealth causality is through labor supply and earnings, making it worthwhile to extend the model with labor supply (and the decision to retire) and earnings. Another interesting extension would be to model access to health insurance and the nature of health insurance, since this may be an important mechanism through which health affects wealth.

\section{References}

1. Adams P, Hurd MD, McFadden D, Merrill A, Ribiero T. Healthy, Wealthy and Wise? Tests for Direct Causal Paths between Health and Socioeconomic Status. Journal of Econometrics 2003;112:3-56.

2. Adda, J. Income and Health over the Life-Cycle: A Dynamic Approach to Evaluate the Importance of Selection and Social Causation. London: mimeo University College; 2003.

3. Adler NE, Boyce T, Cohen S, Folkman S, Kahn RL, Syme SL. Socioeconomic Status and Health: The Challenge of the Gradient. American Psychologist 1994;49(1):15-24. [PubMed: 8122813]

4. Alonso-Borrego C, Arellano M. Symmetrically Normalized Instrumental-Variable Estimation using Panel Data. Journal of Business and Economic Statistics 1999;17:36-49.

5. Arellano, M. Panel Data Econometrics. Oxford: Oxford University Press; 2003.

6. Arellano M, Bond S. Some Tests of Specification for Panel Data: Monte Carlo Evidence and an Application to Employment Equations. Review of Economic Studies 1991;58:277-297.

7. Barker DJP. Maternal Nutrition, Fetal Nutrition and Diseases in Later Life. Nutrition 1997;13(9):807813. [PubMed: 9290095]

8. Blundell R, Bond S. Initial Conditions and Moment Restrictions in Dynamic Panel Data Models. Journal of Econometrics 1998;87:115-143.

9. Chamberlain, G. Panel Data. In: Griliches, Z.; Intriligator, MD., editors. Handbook of Econometrics. Vol. Volume 2. Amsterdam: Elsevier Science; 1984. p. 1247-1318.

10. Deaton AS. Health, Inequality and Economic Development. Journal of Economic Literature 2003;41:113-158.

11. Deaton AS, Paxson C. Aging and Inequality in Income and Health. American Economic Review (Papers and Proceedings) 1998;88(2):248-253.

12. Grossman M. On the Concept of Health Capital and the Demand for Health. Journal of Political Economy 1972;80(2):223-255.

13. Hausman JA. Triangular structural model specification and estimation with application to causality. Journal of Econometrics 2003;112:107-113.

14. Hoynes, H.; Hurd, M.; Chand, H. Household Wealth of the Elderly under Alternative Imputation Procedures. In: Wise, David, editor. Inquiries in the Economics of Aging. Chicago: University of Chicago Press; 1998. p. 229-257.

15. Hurd, MD. Portfolio Holdings of the Elderly. In: Guiso, L.; Haliassos, M.; Jappelli, T., editors. Household Portfolios. Cambridge MA: MIT Press; 2001. p. 431-472.

16. Hurd MD, Kapteyn A. Health, Wealth and the Role of Institutions. Journal of Human Resources 2003;38(2):386-415.

17. Kenkel DS. Health Behavior, Health Knowledge and Schooling. Journal of Political Economy 1991;99(2):287-305.

18. Lantz PM, House JS, Lepkowski JM, Williams DR, Mero RP, Chien JC. Socioeconomic Factors, Health Behaviors, and Mortality. Journal of the American Medical Association 1998;279(21):17031708. [PubMed: 9624022]

19. Lindeboom M, Portrait F, van den Berg G. Individual Mortality and Macro-Economic Conditions from Birth to Death. American Economic Review 2006;96(1):290-302. 
20. Marmot, M. Multi-Level Approaches to Understanding Social Determinants, Chapter 15. In: Berkman, L.; Kawachi, I., editors. Social Epidemiology. Oxford: Oxford University Press; 2000. p. 124-175.

21. Mealli F, Rubin DB. Assumptions allowing the estimation of direct causal effects. Journal of Econometrics 2003;112:79-86.

22. Meer J, Miller DL, Rosen HS. Exploring the Health-Wealth Nexus. Journal of Health Economics 2003;22:713-730. [PubMed: 12946455]

23. Michaud, PC.; van Soest, A. Health and wealth of elderly couples: causality tests using dynamic panel data models, Netspar discussion paper 2007. Tilburg: Netspar; 2007.

24. Nijman, TE.; Verbeek, M. Incomplete Panels and Selection Bias. In: Matyas, L.; Sevestre, P., editors. The Econometrics of Panel Data: Handbook of Theory and Applications. Second Revised Edition. Dordrecht: Kluwer Academic Publishers; 1996. p. 449-490.

25. Ravelli ACJ, van der Meulen JHP, Michels RPJ, Osmond C, Barket DJP, Hales CN, Bleker OP. Glucose Tolerance in Adults after Prenatal Exposure to Famine. Lancet 1998;351:173-176. [PubMed: 9449872]

26. Rust J, Phelan C. How Social Security and Medicare affect Retirement Behavior in a World of Incomplete Markets. Econometrica 1997;64(4):781-831.

27. Smith JP. Healthy Bodies and Thick Wallets: The Dual Relation between Health and Economic Status. Journal of Economic Perspectives 1999;13(2):145-166.

28. Smith, JP. Consequences and Predictors of New Health Events. In: Wise, DA., editor. Analyses in the Economics of Aging. Chicago: University of Chicago Press; 2005. p. 213-240.

29. Wilkinson, RG. Unhealthy Societies: The Afflictions of Inequality. London: Routledge; 1996.

30. Wu S. The Effects of Health Events on the Economic Status of Married Couples. Journal of Human Resources 2003;38(1):219-230.

\section{Appendix A Sample Selection and Descriptive Statistics}

\section{Table A.1}

Sample Composition

\begin{tabular}{lccc}
\hline & Couples & Exit rate (\%) \\
Sample 1992 & 4160 & \\
Exits 1993-1994 & & 419 & 10.07 \\
Sample 1994 & 3741 & & \\
Exits 1995-1996 & & 355 & 9.48 \\
Sample 1996 & 3386 & & \\
Exits 1997-1998 & & 335 & 9.89 \\
Sample 1998 & 3051 & & \\
Exits 1999-2000 & & 278 & 9.11 \\
Sample 2000 & 2773 & & \\
Exits 2001-2002 & & 310 & 11.18 \\
Sample 2002 & 2463 & & \\
\hline
\end{tabular}

Notes: Observations per wave, exits between waves, and exits as a percentage of observations per wave.

Table A.2

Demographic Characteristics in 1992 by Period of Exit from the Panel

\begin{tabular}{lrrrrrr}
\hline Demographics 1992 & No-Exit & Exit 1993 & Exit 1995 & Exit 1997 & Exit 1999 & Exit 2001 \\
\hline Husband & & & & & & \\
\hline Age (years) & 56.7 & 56.9 & 57.7 & 58.1 & 58.7 & 57.8
\end{tabular}




\begin{tabular}{lrrrrrr}
\hline Demographics 1992 & No-Exit & Exit 1993 & Exit 1995 & Exit 1997 & Exit 1999 & Exit 2001 \\
\hline Years of schooling & 12.44 & 11.75 & 11.36 & 11.91 & 11.77 & 11.74 \\
Dummy Hispanic & 0.071 & 0.093 & 0.079 & 0.071 & 0.075 & 0.096 \\
Dummy Black & 0.097 & 0.186 & 0.146 & 0.164 & 0.111 & 0.106 \\
Dummy Not born U.S. & 0.089 & 0.093 & 0.104 & 0.101 & 0.089 & 0.087 \\
Dummy >1 marriage & 0.279 & 0.372 & 0.313 & 0.319 & 0.291 & 0.316 \\
\hline Wife & & & & & & \\
\hline Age (years) & 52.8 & 52.9 & 53.4 & 54.3 & 53.9 & 53.8 \\
Years of schooling & 12.39 & 12.03 & 11.73 & 12.08 & 11.86 & 11.74 \\
Dummy Hispanic & 0.073 & 0.105 & 0.079 & 0.08 & 0.064 & 0.119 \\
Dummy Black & 0.095 & 0.169 & 0.149 & 0.167 & 0.111 & 0.103 \\
Dummy Not born U.S. & 0.099 & 0.107 & 0.101 & 0.119 & 0.061 & 0.112 \\
Dummy >1 marriage & 0.243 & 0.353 & 0.256 & 0.281 & 0.273 & 0.312 \\
Number of couples & 2463 & 419 & 355 & 335 & 278 & 310 \\
\hline
\end{tabular}

Notes: Exit 1993 refers to the subsample exiting the panel between the 1992 and 1994 waves, etc.

\section{Appendix B Constructed Health Indices (CHI)}

The health index is constructed by principle component analysis using 6 covariates: selfreported health, prevalence of severe and mild health conditions, CESD scores and the number of ADLs. This is performed for husbands and wives separately, pooling the data across all waves. One factor is retained from the analysis. Factor scores are presented in Table 14 along with Eigenvalues. The variable that scores highest is self-reported health, but other variables also contribute. We also experimented with alternative health indices using fewer health variables; this gave similar results of the tests for causal effects. The constructed health index is normalized to have mean 0 and variance 1 ; it varies between -3 and 5 and the distribution tends to be skewed toward zero.

Table B.1

Results of Principal Component Analysis

\begin{tabular}{lrrcr}
\hline Health Indicators (husbands) & scoring & 1st factor & Uniqueness Factors & Eigenvalues \\
\hline Self-reported health & 0.37 & 0.79 & 0.37 1st & 2.14 \\
Severe condition (ever had) & 0.3 & 0.64 & 0.59 2nd & 0.89 \\
Mild condition (ever had) & 0.3 & 0.65 & 0.58 3rd & 0.75 \\
CESD score & 0.27 & 0.57 & 0.67 th & 0.7 \\
ADL & 0.28 & 0.6 & 0.645 th & 0.52 \\
\hline Retained Factor 1 & $\mathrm{N}$ & 20373 & LR (p-val)<0.001 \\
\hline Health Indicators (wives) & scoring & 1 st factor & Uniqueness Factors & \multirow{2}{*}{ Eigenvalues } \\
\hline Self-reported health & 0.35 & 0.79 & 0.37 1st & 2.24 \\
Severe condition (ever had) & 0.26 & 0.58 & 0.66 2nd & 0.85 \\
Mild condition (ever had) & 0.31 & 0.7 & 0.51 3rd & 0.74
\end{tabular}




\begin{tabular}{lrrcr}
\hline Health Indicators (husbands) & scoring & 1st factor & Uniqueness Factors & Eigenvalues \\
\hline CESD score & 0.28 & 0.62 & 0.62 4th & 0.68 \\
ADL & 0.28 & 0.63 & 0.65 th & 0.5 \\
\hline Retained Factor 1 & $\mathrm{N}$ & 20373 & \multicolumn{2}{c}{ LR (p-val) $<0.001$} \\
\hline
\end{tabular}

\section{Appendix C: Regression Results Corresponding to Table 9 in the Paper}

This document contains detailed regression results for the estimations in Table 9 of the paper. Point estimates are reported along with t-values. For each spouse, two sets of estimates are presented, one which includes only one lag of the spouse's health and the other with three lags. Time effects are included in each specification. The definition of the dependent variable and the estimation method used for each condition is given below.

\begin{tabular}{|l|l|l|}
\hline Health Variable & Abbreviation & Estimation Method \\
\hline Health Index & CHI & Linear regression \\
\hline $\begin{array}{l}\text { Onset of Severe health } \\
\text { condition }\end{array}$ & Severe & Probit \\
\hline $\begin{array}{l}\text { Onset of a Mild health } \\
\text { condition }\end{array}$ & Mild & Probit \\
\hline $\begin{array}{l}\text { Self-reported health (5 point } \\
\text { scale) }\end{array}$ & SRH & Ordered Probit \\
\hline $\begin{array}{l}\text { Mental Health index } \\
\text { (CESD) 7 points scale }\end{array}$ & CESD & Ordered Probit \\
\hline $\begin{array}{l}\text { Number of limitation in } \\
\text { activities of daily living }\end{array}$ & ADL & Ordered Probit \\
\hline
\end{tabular}

The abbreviation $\mathrm{m}$ refers to the husband and $\mathrm{f}$ for the wife. The definition of each control variable (other than health and wealth defined in the text) is given below.

\begin{tabular}{|l|l|l|}
\hline Variable & Definition & Type \\
\hline Age & Age if respondent & Years \\
\hline years ed & Years of education & Years \\
\hline Black & Respondent is African American & $(0,1)$ \\
\hline Hispanic & Respondent is Hispanic & $(0,1)$ \\
\hline Immigrant & Respondent born outside US & $(0,1)$ \\
\hline Smoke & Respondent currently smokes & $(0,1)$ \\
\hline Smoke ever & Respondent has ever smoked & $(0,1)$ \\
\hline Drink & Respondent drinks regularly & $(0,1)$ \\
\hline Bmi & Body mass index & $\mathrm{Kg} / \mathrm{m}^{2}($ Range: $15-50)$ \\
\hline
\end{tabular}


Table C.1

Results for Husbands with One Lag of Health Index

\begin{tabular}{|c|c|c|c|c|c|c|}
\hline Variable & CHI & severe & mild & SRH & CESD & ADL \\
\hline \multirow[t]{2}{*}{ wealth $(t-1)$} & -0.003717 & -0.002619 & 0.0106028 & 0.0037681 & -0.009949 & -0.019954 \\
\hline & -0.53 & -0.16 & 0.78 & 0.34 & -1.03 & -1.41 \\
\hline \multirow[t]{2}{*}{ wealth $(\mathrm{t}-2)$} & -0.004192 & -0.005137 & -0.010463 & -0.002933 & -0.013124 & 0.0003371 \\
\hline & -2 & -1 & -2.52 & -0.75 & -4.25 & 0.08 \\
\hline \multirow[t]{2}{*}{ wealth $(\mathrm{t}-1) \times \mathrm{t}$} & 0.0010807 & 0.0004781 & -0.003719 & -0.001569 & 0.0014996 & 0.0037277 \\
\hline & 0.56 & 0.11 & -0.94 & -0.49 & 0.53 & 0.9 \\
\hline \multirow[t]{2}{*}{ health $\mathrm{m}(\mathrm{t}-1)$} & 0.8307919 & 0.0230928 & -0.002404 & 1.0288175 & 0.4445708 & 0.5019755 \\
\hline & 34.65 & 0.38 & -0.04 & 24.87 & 12.25 & 9.62 \\
\hline \multirow[t]{2}{*}{ health $\mathrm{m}(\mathrm{t}-1) \times \mathrm{t}$} & 0.0064282 & 0.0084413 & -0.017408 & -0.050846 & 0.0076265 & 0.0247717 \\
\hline & 1 & 0.52 & -1.15 & -4.68 & 0.78 & 1.74 \\
\hline \multirow[t]{2}{*}{ health $\mathrm{f}(\mathrm{t}-1)$} & 0.0350959 & 0.1557963 & 0.0389062 & 0.0343844 & 0.1244257 & 0.0835784 \\
\hline & 1.58 & 2.53 & 0.71 & 0.87 & 3.48 & 1.57 \\
\hline \multirow[t]{2}{*}{ health $\mathrm{f}(\mathrm{t}-2)$} & 0.0270486 & -0.042 & 0.0114232 & 0.0663221 & 0.0033204 & 0.0248633 \\
\hline & 2.08 & -1.23 & 0.38 & 3.03 & 0.16 & 0.82 \\
\hline \multirow[t]{2}{*}{ health $\mathrm{f}(\mathrm{t}-1) \times \mathrm{t}$} & -0.008944 & -0.027276 & -0.009818 & -0.015933 & -0.019012 & -0.013817 \\
\hline & -1.69 & -1.78 & -0.7 & -1.6 & -2.02 & -1.01 \\
\hline \multirow[t]{2}{*}{ age $\mathrm{m}$} & 0.0094617 & 0.0233079 & -0.001527 & $6.691 \mathrm{E}-05$ & -0.007298 & 0.016298 \\
\hline & 7.35 & 6.28 & -0.48 & 0.02 & -2.14 & 3.14 \\
\hline \multirow[t]{2}{*}{ age $\mathrm{f}$} & -0.000772 & 0.0038342 & 0.0020272 & -0.001831 & -0.006134 & -0.00181 \\
\hline & -0.71 & 1.12 & 0.7 & -0.65 & -2.02 & -0.41 \\
\hline \multirow[t]{2}{*}{ years ed m } & -0.005425 & 0.0081413 & -0.011212 & -0.039346 & -0.02813 & -0.004426 \\
\hline & -2.62 & 1.25 & -2.04 & -7.51 & -4.81 & -0.57 \\
\hline \multirow[t]{2}{*}{ years ed $f$} & -0.005717 & -0.008121 & 0.0001648 & -0.014471 & -0.002428 & -0.012433 \\
\hline & -2.27 & -1.01 & 0.02 & -2.25 & -0.33 & -1.27 \\
\hline \multirow[t]{2}{*}{ black m } & 0.0518885 & -0.128447 & 0.1115348 & -0.111619 & 0.2885855 & 0.1100421 \\
\hline & 0.85 & -0.69 & 0.59 & -0.56 & 1.59 & 0.34 \\
\hline \multirow[t]{2}{*}{ black f } & -0.03428 & 0.1120587 & -0.022145 & 0.2305981 & -0.114488 & -0.208229 \\
\hline & -0.56 & 0.6 & -0.12 & 1.14 & -0.63 & -0.65 \\
\hline \multirow[t]{2}{*}{ hispanic $\mathrm{m}$} & 0.0309315 & -0.284308 & 0.0493436 & 0.074238 & 0.2465078 & 0.1403158 \\
\hline & 0.72 & -1.93 & 0.49 & 0.87 & 2.43 & 0.98 \\
\hline \multirow[t]{2}{*}{ hispanic $\mathrm{f}$} & -0.05735 & -0.015001 & 0.0140196 & 0.0082034 & -0.058711 & -0.113554 \\
\hline & -1.4 & -0.11 & 0.13 & 0.1 & -0.59 & -0.8 \\
\hline \multirow[t]{2}{*}{ immigrant $\mathrm{m}$} & -0.02677 & -0.108872 & -0.077644 & 0.028339 & -0.00412 & 0.0934619 \\
\hline & -1.21 & -1.32 & -1.23 & 0.49 & -0.06 & 0.93 \\
\hline \multirow[t]{2}{*}{ immigrant $f$} & -0.002171 & 0.1023388 & 0.0263025 & -0.06146 & 0.1250372 & -0.099016 \\
\hline & -0.1 & 1.35 & 0.41 & -1.06 & 1.88 & -0.97 \\
\hline \multirow[t]{2}{*}{ smoke m (t-1) } & 0.0401375 & 0.0731849 & 0.0780618 & 0.0488526 & 0.0215702 & 0.013411 \\
\hline & 3.97 & 1.96 & 2.39 & 1.63 & 0.59 & 0.27 \\
\hline smoke $\mathrm{f}(\mathrm{t}-2)$ & 0.0033427 & 0.0621074 & -0.026113 & -0.051336 & -0.001418 & 0.0178524 \\
\hline
\end{tabular}

$J$ Health Econ. Author manuscript; available in PMC 2010 May 11. 


\begin{tabular}{lrrrrrr}
\hline Variable & CHI & severe & mild & SRH & CESD & ADL \\
\cline { 2 - 7 } & 0.35 & 1.86 & -0.9 & -1.94 & -0.05 & 0.41 \\
smoke ever m (t-1) & -0.041944 & -0.047278 & -0.046611 & -0.187076 & 0.0178957 & -0.220824 \\
& -3.95 & -1.3 & -1.46 & -7.84 & 0.67 & -5.29 \\
smoke ever f (t-1) & -0.007921 & -0.013626 & -0.011662 & -0.026314 & -0.023903 & 0.0350452 \\
& -0.73 & -0.37 & -0.37 & -1.13 & -0.92 & 0.89 \\
drink m (t-1) & -0.027 & -0.053959 & -0.018592 & -0.051672 & 0.039328 & -0.04314 \\
& -2.28 & -1.4 & -0.55 & -1.89 & 1.3 & -0.99 \\
drink f (t-1) & 0.0125151 & -0.020476 & 0.035258 & -0.01411 & 0.0057942 & 0.0145961 \\
& 1.1 & -0.53 & 1.07 & -0.52 & 0.19 & 0.33 \\
bmi m (t-1) & 0.0083845 & 0.010081 & 0.0238462 & 0.0038602 & 0.0009386 & 0.0179303 \\
& 6.13 & 2.54 & 7.14 & 1.29 & 0.26 & 3.61 \\
bmi f (t-1) & -0.000295 & 0.002157 & -0.001362 & 0.0065911 & -0.004073 & -0.003187 \\
& -0.33 & 0.7 & -0.51 & 2.66 & -1.52 & -0.81 \\
time effects & yes & yes & yes & yes & yes & yes \\
\hline
\end{tabular}

Table C.2

Results for Husbands with Three Lags of Health Index

\begin{tabular}{|c|c|c|c|c|c|c|}
\hline Variable & CHI & severe & mild & SRH & CESD & ADL \\
\hline \multirow[t]{2}{*}{ wealth $(\mathrm{t}-1)$} & -0.00141 & 0.0240816 & 0.034056 & 0.0096667 & -0.008412 & -0.010074 \\
\hline & -0.13 & 0.83 & 1.34 & 0.48 & -0.49 & -0.47 \\
\hline \multirow[t]{2}{*}{ wealth $(\mathrm{t}-2)$} & -0.000162 & -0.001964 & -0.009409 & 0.0048024 & -0.013798 & 0.0001653 \\
\hline & -0.06 & -0.31 & -1.82 & 0.99 & -3.39 & 0.03 \\
\hline \multirow[t]{2}{*}{ wealth $(t-1) \times t$} & 0.0001264 & -0.006107 & -0.009123 & -0.003755 & 0.0011652 & 0.0008194 \\
\hline & 0.05 & -0.86 & -1.43 & -0.72 & 0.26 & 0.15 \\
\hline \multirow[t]{2}{*}{ health $\mathrm{m}(\mathrm{t}-1)$} & 0.6290225 & 0.0234953 & 0.180561 & 0.7574355 & 0.2637151 & 0.555344 \\
\hline & 14.91 & 0.22 & 1.84 & 10.81 & 4.61 & 5.84 \\
\hline \multirow[t]{2}{*}{ health $\mathrm{m}(\mathrm{t}-2)$} & 0.258741 & 0.0697518 & -0.045847 & 0.2630267 & 0.1449218 & 0.1666523 \\
\hline & 15.01 & 1.66 & -1.16 & 9.67 & 5.82 & 4.6 \\
\hline \multirow[t]{2}{*}{ health $\mathrm{m}(\mathrm{t}-3)$} & 0.1330701 & 0.0346194 & -0.012496 & 0.1998138 & 0.0475438 & 0.0068306 \\
\hline & 8.05 & 0.86 & -0.33 & 6.94 & 1.78 & 0.18 \\
\hline \multirow[t]{2}{*}{ health $\mathrm{m}(\mathrm{t}-1) \times \mathrm{t}$} & -0.011208 & -0.008269 & -0.049629 & -0.05688 & 0.0189208 & -0.014277 \\
\hline & -1.11 & -0.33 & -2.11 & -3.4 & 1.31 & -0.62 \\
\hline \multirow[t]{2}{*}{ health $\mathrm{f}(\mathrm{t}-1)$} & 0.0271181 & 0.2053874 & -0.083019 & 0.0869819 & 0.0351311 & -0.063876 \\
\hline & 0.79 & 1.98 & -0.88 & 1.33 & 0.61 & -0.7 \\
\hline \multirow[t]{2}{*}{ health $\mathrm{f}(\mathrm{t}-2)$} & 0.0042642 & -0.039513 & 0.0152052 & 0.0293606 & -0.003645 & 0.0498515 \\
\hline & 0.32 & -1.01 & 0.45 & 1.19 & -0.15 & 1.48 \\
\hline \multirow[t]{2}{*}{ health $\mathrm{f}(\mathrm{t}-1) \times \mathrm{t}$} & -0.005097 & -0.037794 & 0.0172338 & -0.023614 & 0.0026034 & 0.0148942 \\
\hline & -0.62 & -1.52 & 0.76 & -1.51 & 0.18 & 0.69 \\
\hline \multirow[t]{2}{*}{ age $m$} & 0.0074682 & 0.0217574 & -0.002785 & -0.000173 & -0.010466 & 0.0146336 \\
\hline & 4.74 & 4.93 & -0.72 & -0.05 & -2.78 & 2.53 \\
\hline
\end{tabular}

J Health Econ. Author manuscript; available in PMC 2010 May 11. 


\begin{tabular}{|c|c|c|c|c|c|c|}
\hline Variable & $\mathrm{CHI}$ & severe & mild & SRH & CESD & ADL \\
\hline \multirow[t]{2}{*}{ age $\mathrm{f}$} & -0.00103 & 0.0006432 & -0.000509 & -0.005142 & -0.005392 & 0.0003743 \\
\hline & -0.77 & 0.16 & -0.15 & -1.59 & -1.57 & 0.08 \\
\hline \multirow[t]{2}{*}{ years ed m } & -0.00177 & 0.0075739 & -0.007691 & -0.036394 & -0.024796 & -0.000589 \\
\hline & -0.66 & 0.98 & -1.13 & -5.86 & -3.75 & -0.07 \\
\hline \multirow[t]{2}{*}{ years ed $\mathrm{f}$} & -0.002453 & 0.0023345 & -0.00391 & -0.008147 & -0.003415 & -0.004546 \\
\hline & -0.78 & 0.24 & -0.46 & -1.06 & -0.42 & -0.39 \\
\hline \multirow[t]{2}{*}{ black m } & 0.1002104 & -0.101007 & 0.1740773 & -0.04236 & 0.3853315 & 0.0789728 \\
\hline & 1.71 & -0.51 & 0.75 & -0.17 & 2.04 & 0.19 \\
\hline \multirow[t]{2}{*}{ black f } & -0.07263 & 0.0984743 & -0.119604 & 0.2058426 & -0.177858 & -0.223443 \\
\hline & -1.22 & 0.5 & -0.51 & 0.83 & -0.93 & -0.53 \\
\hline \multirow[t]{2}{*}{ hispanic $\mathrm{m}$} & 0.0474845 & -0.186831 & 0.140274 & 0.0715463 & 0.2910932 & 0.1423363 \\
\hline & 0.91 & -1.15 & 1.17 & 0.73 & 2.66 & 0.89 \\
\hline \multirow[t]{2}{*}{ hispanic $\mathrm{f}$} & -0.028149 & 0.0167635 & -0.010199 & 0.0741416 & -0.097407 & -0.003919 \\
\hline & -0.54 & 0.11 & -0.08 & 0.74 & -0.9 & -0.02 \\
\hline \multirow[t]{2}{*}{ immigrant $\mathrm{m}$} & -0.051317 & -0.155949 & -0.100414 & 0.0289955 & -0.041137 & -0.013202 \\
\hline & -1.96 & -1.52 & -1.32 & 0.44 & -0.53 & -0.11 \\
\hline \multirow[t]{2}{*}{ immigrant $\mathrm{f}$} & 0.0051558 & 0.0356805 & -0.020398 & -0.077611 & 0.1556862 & -0.077862 \\
\hline & 0.2 & 0.37 & -0.27 & -1.16 & 2.14 & -0.69 \\
\hline \multirow[t]{2}{*}{ smoke m (t-1) } & 0.0256225 & 0.1197533 & 0.053342 & 0.0278459 & 0.0022318 & -0.025818 \\
\hline & 1.97 & 2.73 & 1.39 & 0.82 & 0.06 & -0.46 \\
\hline \multirow[t]{2}{*}{ smoke $\mathrm{f}(\mathrm{t}-2)$} & 0.0081269 & 0.0602367 & -0.004453 & -0.056573 & 0.0081074 & 0.0371666 \\
\hline & 0.66 & 1.54 & -0.13 & -1.84 & 0.23 & 0.76 \\
\hline \multirow[t]{2}{*}{ smoke ever m (t-1) } & -0.031522 & -0.035081 & -0.07148 & -0.1769 & 0.02909 & -0.216687 \\
\hline & -2.6 & -0.86 & -2.01 & -6.44 & 0.96 & -4.83 \\
\hline \multirow[t]{2}{*}{ smoke ever $\mathrm{f}(\mathrm{t}-1)$} & -0.005049 & -0.01755 & -0.031455 & -0.032551 & -0.011192 & 0.0599984 \\
\hline & -0.41 & -0.43 & -0.89 & -1.23 & -0.38 & 1.31 \\
\hline \multirow[t]{2}{*}{ drink $m(t-1)$} & -0.03375 & -0.080309 & -0.046985 & -0.071258 & 0.0346547 & -0.021915 \\
\hline & -2.44 & -1.78 & -1.22 & -2.27 & 1.01 & -0.43 \\
\hline \multirow[t]{2}{*}{ drink $f(t-1)$} & 0.015395 & 0.015109 & 0.0161849 & -0.013619 & 0.0115963 & -0.001363 \\
\hline & 1.15 & 0.33 & 0.42 & -0.43 & 0.33 & -0.03 \\
\hline \multirow[t]{2}{*}{$\operatorname{bmi} \mathrm{m}(\mathrm{t}-1)$} & 0.0055822 & 0.0072677 & 0.0210127 & 0.0013175 & 0.0009218 & 0.0110466 \\
\hline & 3.48 & 1.59 & 5.31 & 0.38 & 0.23 & 2.01 \\
\hline \multirow[t]{2}{*}{$\operatorname{bmi} f(t-1)$} & -0.00027 & 0.0018102 & -0.001432 & 0.007247 & -0.006029 & -0.001351 \\
\hline & -0.24 & 0.51 & -0.45 & 2.53 & -2.07 & -0.3 \\
\hline time effects & yes & yes & yes & yes & yes & yes \\
\hline
\end{tabular}

Table C.3

Results for Wives with One Lag of Health Index

\begin{tabular}{lrrrrrr}
\hline Variable & CHI & severe & mild & SRH & CESD & ADL \\
\cline { 2 - 7 } wealth $(\mathrm{t}-1)$ & -0.005637 & -0.012161 & -0.005875 & -0.004235 & -0.000917 & -0.021982
\end{tabular}

J Health Econ. Author manuscript; available in PMC 2010 May 11. 


\begin{tabular}{|c|c|c|c|c|c|c|}
\hline \multirow[t]{2}{*}{ Variable } & CHI & severe & mild & SRH & CESD & ADL \\
\hline & -0.95 & -0.82 & -0.45 & -0.42 & -0.1 & -1.67 \\
\hline \multirow[t]{2}{*}{ wealth (t-2) } & -0.005561 & -0.005328 & -0.012059 & -0.006688 & -0.003608 & -0.006559 \\
\hline & -2.87 & -0.97 & -2.84 & -1.9 & -1.13 & -1.45 \\
\hline \multirow[t]{2}{*}{ wealth $(t-1) \times t$} & 0.0010299 & 0.0004028 & 0.0014409 & 0.0005375 & $9.649 \mathrm{E}-05$ & 0.0078965 \\
\hline & 0.65 & 0.1 & 0.38 & 0.19 & 0.04 & 1.92 \\
\hline \multirow[t]{2}{*}{ health $\mathrm{f}(\mathrm{t}-1)$} & 0.8848301 & 0.2095801 & -0.052728 & 1.0760978 & 0.5545131 & 0.6367245 \\
\hline & 37.45 & 3.45 & -0.96 & 23.8 & 15.48 & 12.99 \\
\hline \multirow[t]{2}{*}{ health $\mathrm{f}(\mathrm{t}-1) \times \mathrm{t}$} & -0.007958 & -0.012018 & -0.00095 & -0.062018 & -0.021625 & 0.005174 \\
\hline & -1.28 & -0.73 & -0.06 & -5.4 & -2.33 & 0.39 \\
\hline \multirow[t]{2}{*}{ health $\mathrm{m}(\mathrm{t}-1)$} & -0.018634 & -0.031494 & 0.0754542 & 0.0406816 & 0.0384972 & -0.031317 \\
\hline & -0.93 & -0.43 & 1.32 & 1.1 & 1.05 & -0.55 \\
\hline \multirow[t]{2}{*}{ health $\mathrm{m}(\mathrm{t}-2)$} & 0.0315545 & 0.0367209 & -0.014694 & 0.0514403 & 0.0334398 & 0.0380018 \\
\hline & 2.61 & 0.97 & -0.49 & 2.5 & 1.61 & 1.21 \\
\hline \multirow[t]{2}{*}{ health $m(t-1) \times t$} & 0.0034385 & 0.0066537 & -0.017073 & -0.010135 & -0.000215 & 0.0057538 \\
\hline & 0.66 & 0.35 & -1.14 & -1.03 & -0.02 & 0.38 \\
\hline \multirow[t]{2}{*}{ age $\mathrm{m}$} & -0.000677 & 0.0071334 & 0.0007793 & 0.0001516 & -0.002164 & -0.000811 \\
\hline & -0.6 & 1.68 & 0.25 & 0.05 & -0.72 & -0.18 \\
\hline \multirow[t]{2}{*}{ age $\mathrm{f}$} & 0.0044226 & 0.0112336 & 0.0027156 & 0.0024985 & -0.008273 & -0.001053 \\
\hline & 4.55 & 2.8 & 0.92 & 0.93 & -2.94 & -0.25 \\
\hline \multirow[t]{2}{*}{ years ed $\mathrm{m}$} & -0.002447 & 0.0025573 & -0.001313 & -0.023107 & 0.0073616 & -0.013474 \\
\hline & -1.28 & 0.34 & -0.24 & -4.53 & 1.37 & -1.85 \\
\hline \multirow[t]{2}{*}{ years ed $\mathrm{f}$} & -0.0097 & -0.009556 & -0.023376 & -0.035868 & -0.038573 & -0.0051 \\
\hline & -4.19 & -1.02 & -3.5 & -5.6 & -5.77 & -0.52 \\
\hline \multirow[t]{2}{*}{ black m } & -0.013153 & -0.384921 & -0.11749 & -0.321489 & -0.180977 & 0.0074667 \\
\hline & -0.22 & -1.79 & -0.64 & -2.26 & -1.02 & 0.03 \\
\hline \multirow[t]{2}{*}{ black $\mathrm{f}$} & 0.0420514 & 0.3261831 & 0.1127951 & 0.4452369 & 0.244576 & 0.117176 \\
\hline & 0.68 & 1.52 & 0.61 & 3.08 & 1.38 & 0.46 \\
\hline \multirow[t]{2}{*}{ hispanic $\mathrm{m}$} & -0.045505 & -0.226535 & -0.132031 & -0.151723 & 0.173364 & -0.054931 \\
\hline & -1.55 & -1.51 & -1.48 & -1.74 & 1.78 & -0.38 \\
\hline \multirow[t]{2}{*}{ hispanic $\mathrm{f}$} & -0.003923 & 0.1600293 & 0.0652195 & 0.2520215 & -0.077463 & 0.0464081 \\
\hline & -0.13 & 1.12 & 0.78 & 2.92 & -0.78 & 0.31 \\
\hline \multirow[t]{2}{*}{ immigrant $\mathrm{m}$} & -0.007354 & -0.152988 & 0.1777753 & 0.1288188 & 0.0783571 & -0.018937 \\
\hline & -0.36 & -1.46 & 2.74 & 2.07 & 1.36 & -0.19 \\
\hline \multirow[t]{2}{*}{ immigrant $f$} & 0.0253411 & -0.200151 & -0.093162 & 0.0901261 & 0.1711329 & 0.0825094 \\
\hline & 1.22 & -2.01 & -1.41 & 1.47 & 3.05 & 0.82 \\
\hline \multirow[t]{2}{*}{ smoke m (t-1) } & -0.00284 & 0.0413161 & -0.041284 & -0.000872 & -0.029278 & -0.008731 \\
\hline & -0.28 & 0.89 & -1.25 & -0.03 & -0.91 & -0.18 \\
\hline \multirow[t]{2}{*}{ smoke f $(\mathrm{t}-2)$} & 0.050526 & 0.138876 & 0.0781082 & 0.0727508 & 0.0655424 & -0.009018 \\
\hline & 5.44 & 3.49 & 2.63 & 2.68 & 2.33 & -0.2 \\
\hline \multirow[t]{2}{*}{ smoke ever $\mathrm{m}(\mathrm{t}-1)$} & -0.00947 & -0.034017 & 0.0258259 & -0.020279 & -0.017111 & -0.046365 \\
\hline & -0.9 & -0.79 & 0.82 & -0.84 & -0.7 & -1.11 \\
\hline smoke ever $\mathrm{f}(\mathrm{t}-1)$ & -0.043952 & -0.085772 & -0.065142 & -0.207649 & -0.01821 & -0.161766 \\
\hline
\end{tabular}

$J$ Health Econ. Author manuscript; available in PMC 2010 May 11. 


\begin{tabular}{lrrrrrr}
\hline Variable & CHI & severe & mild & SRH & CESD & ADL \\
\cline { 2 - 7 } & -4.38 & -1.99 & -2.06 & -8.77 & -0.74 & -3.78 \\
drink m (t-1) & -0.010932 & -0.018411 & -0.014221 & 0.010613 & -0.023448 & -0.000315 \\
& -0.94 & -0.42 & -0.43 & 0.38 & -0.81 & -0.01 \\
drink f (t-1) & -0.035181 & -0.031075 & 0.0233157 & -0.159664 & 0.0680667 & -0.142348 \\
& -3.18 & -0.67 & 0.68 & -5.86 & 2.3 & -2.98 \\
bmi m (t-1) & -0.000755 & -0.000768 & 0.0053829 & 0.0051756 & 0.0015995 & 0.0030998 \\
& -0.66 & -0.17 & 1.62 & 1.75 & 0.48 & 0.64 \\
bmi f (t-1) & 0.0068701 & -0.000597 & 0.0112437 & 0.0069544 & -0.001757 & 0.0125799 \\
& 6.73 & -0.16 & 4.16 & 2.67 & -0.69 & 3.37 \\
time effects & yes & yes & yes & yes & yes & yes \\
\hline
\end{tabular}

Table C.4

Results for Wives with Three Lags of Health Index

\begin{tabular}{|c|c|c|c|c|c|c|}
\hline Variable & CHI & severe & mild & SRH & CESD & ADL \\
\hline \multirow[t]{2}{*}{ wealth $(\mathrm{t}-1)$} & 0.0011671 & -0.03624 & -0.03293 & 0.0119441 & 0.01549 & -0.00123 \\
\hline & 0.11 & -1.32 & -1.39 & 0.66 & 1.04 & -0.05 \\
\hline \multirow[t]{2}{*}{ wealth (t-2) } & -0.00465 & -0.006794 & -0.009634 & -0.004962 & -0.004904 & -0.002656 \\
\hline & -2.07 & -1.06 & -1.83 & -1.12 & -1.26 & -0.45 \\
\hline \multirow[t]{2}{*}{ wealth $(t-1) \times t$} & -0.000284 & 0.0062961 & 0.0077331 & -0.002987 & -0.003791 & 0.0028365 \\
\hline & -0.11 & 0.9 & 1.26 & -0.65 & -1 & 0.4 \\
\hline \multirow[t]{2}{*}{ health $\mathrm{f}(\mathrm{t}-1)$} & 0.6343558 & 0.0946028 & -0.133766 & 0.8035256 & 0.318771 & 0.494627 \\
\hline & 15.1 & 0.89 & -1.41 & 10.85 & 5.6 & 6.06 \\
\hline \multirow[t]{2}{*}{ health $\mathrm{f}(\mathrm{t}-2)$} & 0.2478683 & 0.0517714 & -0.050821 & 0.2279767 & 0.1684452 & 0.1936606 \\
\hline & 12.8 & 1.08 & -1.22 & 7.78 & 6.52 & 5.13 \\
\hline \multirow[t]{2}{*}{ health $\mathrm{f}(\mathrm{t}-3)$} & 0.1421688 & -0.014994 & -0.025344 & 0.1834406 & -0.013875 & 0.0453467 \\
\hline & 8.88 & -0.32 & -0.64 & 6.3 & -0.53 & 1.23 \\
\hline \multirow[t]{2}{*}{ health $\mathrm{f}(\mathrm{t}-1) \times \mathrm{t}$} & -0.01559 & 0.0075329 & 0.0313471 & -0.062498 & 0.0067987 & -0.000736 \\
\hline & -1.58 & 0.3 & 1.38 & -3.41 & 0.48 & -0.04 \\
\hline \multirow[t]{2}{*}{ health $\mathrm{m}(\mathrm{t}-1)$} & 0.0343441 & -0.039688 & 0.0574299 & 0.1524187 & -0.001212 & 0.0234802 \\
\hline & 0.99 & -0.32 & 0.59 & 2.41 & -0.02 & 0.24 \\
\hline \multirow[t]{2}{*}{ health $\mathrm{m}(\mathrm{t}-2)$} & 0.0010413 & 0.0175751 & -0.002578 & 0.0233274 & 0.0262153 & -0.002058 \\
\hline & 0.08 & 0.41 & -0.07 & 0.99 & 1.12 & -0.06 \\
\hline \multirow[t]{2}{*}{ health $\mathrm{m}(\mathrm{t}-1) \times \mathrm{t}$} & -0.005705 & 0.0119204 & -0.01595 & -0.033438 & 0.0100104 & $9.282 \mathrm{E}-05$ \\
\hline & -0.67 & 0.4 & -0.68 & -2.16 & 0.65 & 0 \\
\hline \multirow[t]{2}{*}{ age $m$} & -0.0009 & 0.0063698 & -0.000818 & 0.0008919 & -0.0035 & -0.003588 \\
\hline & -0.64 & 1.25 & -0.21 & 0.25 & -1.07 & -0.68 \\
\hline \multirow[t]{2}{*}{ age $\mathrm{f}$} & 0.0031309 & 0.0110403 & 0.0046264 & -0.000799 & -0.005957 & -0.001182 \\
\hline & 2.51 & 2.46 & 1.29 & -0.25 & -1.92 & -0.23 \\
\hline \multirow[t]{2}{*}{ years ed $\mathrm{m}$} & -0.000634 & 0.0108637 & -0.004559 & -0.023722 & 0.009554 & -0.014239 \\
\hline & -0.26 & 1.28 & -0.7 & -4.02 & 1.58 & -1.67 \\
\hline
\end{tabular}

J Health Econ. Author manuscript; available in PMC 2010 May 11. 


\begin{tabular}{|c|c|c|c|c|c|c|}
\hline Variable & $\mathrm{CHI}$ & severe & mild & SRH & CESD & ADL \\
\hline \multirow[t]{2}{*}{ years ed $\mathrm{f}$} & -0.005371 & -0.017494 & -0.021649 & -0.032283 & -0.030019 & 0.0012607 \\
\hline & -1.72 & -1.56 & -2.75 & -4.23 & -3.98 & 0.11 \\
\hline \multirow[t]{2}{*}{ black m } & 0.0211106 & -0.756788 & -0.27658 & -0.220447 & -0.193857 & 0.0272502 \\
\hline & 0.3 & -2.94 & -1.13 & -1.37 & -0.98 & 0.11 \\
\hline \multirow[t]{2}{*}{ black $\mathrm{f}$} & 0.0089432 & 0.6879845 & 0.2130893 & 0.3502486 & 0.2766444 & 0.1300439 \\
\hline & 0.13 & 2.68 & 0.87 & 2.14 & 1.4 & 0.5 \\
\hline \multirow[t]{2}{*}{ hispanic $\mathrm{m}$} & -0.054988 & -0.226467 & -0.133011 & -0.179868 & 0.1480538 & -0.064378 \\
\hline & -1.38 & -1.35 & -1.26 & -1.86 & 1.34 & -0.41 \\
\hline \multirow[t]{2}{*}{ hispanic $\mathrm{f}$} & 0.0111042 & 0.11571 & 0.1333388 & 0.2431101 & -0.013253 & 0.0568621 \\
\hline & 0.29 & 0.73 & 1.31 & 2.46 & -0.12 & 0.36 \\
\hline \multirow[t]{2}{*}{ immigrant $\mathrm{m}$} & -0.019827 & -0.144177 & 0.1979015 & 0.1321765 & 0.0818822 & -0.099386 \\
\hline & -0.71 & -1.2 & 2.49 & 1.84 & 1.25 & -0.84 \\
\hline \multirow[t]{2}{*}{ immigrant $\mathrm{f}$} & 0.0188738 & -0.264498 & -0.117675 & 0.0593326 & 0.1691237 & 0.1773511 \\
\hline & 0.71 & -2.25 & -1.49 & 0.83 & 2.71 & 1.56 \\
\hline \multirow[t]{2}{*}{ smoke m (t-1) } & 0.0096939 & 0.0489282 & -0.011031 & 0.0048805 & -0.012001 & 0.0053887 \\
\hline & 0.75 & 0.9 & -0.28 & 0.14 & -0.34 & 0.1 \\
\hline \multirow[t]{2}{*}{ smoke $f(t-2)$} & 0.0461972 & 0.1310734 & 0.1125309 & 0.070681 & 0.0870746 & -0.035043 \\
\hline & 3.84 & 2.79 & 3.2 & 2.28 & 2.78 & -0.67 \\
\hline \multirow[t]{2}{*}{ smoke ever m ( $\mathrm{t}-1)$} & -0.015124 & -0.054122 & 0.0199105 & -0.03293 & -0.025881 & -0.038066 \\
\hline & -1.28 & -1.15 & 0.57 & -1.2 & -0.93 & -0.82 \\
\hline \multirow[t]{2}{*}{ smoke ever $\mathrm{f}(\mathrm{t}-1)$} & -0.033104 & -0.075404 & -0.051832 & -0.2261 & -0.025249 & -0.126021 \\
\hline & -2.9 & -1.57 & -1.43 & -8.39 & -0.91 & -2.56 \\
\hline \multirow[t]{2}{*}{ drink $m(t-1)$} & -0.008483 & -0.038474 & -0.024371 & 0.0183829 & -0.026655 & 0.0250471 \\
\hline & -0.6 & -0.75 & -0.62 & 0.57 & -0.8 & 0.47 \\
\hline \multirow[t]{2}{*}{$\operatorname{drink} \mathrm{f}(\mathrm{t}-1)$} & -0.03871 & -0.039678 & 0.025692 & -0.179065 & 0.0578726 & -0.172209 \\
\hline & -2.9 & -0.72 & 0.64 & -5.63 & 1.73 & -3.03 \\
\hline \multirow[t]{2}{*}{ bmi m (t-1) } & 0.0001202 & -0.003071 & 0.0114577 & 0.0052951 & 0.0020634 & 0.0027734 \\
\hline & 0.08 & -0.57 & 2.97 & 1.54 & 0.56 & 0.49 \\
\hline \multirow[t]{2}{*}{$\operatorname{bmi} f(t-1)$} & 0.00397 & 0.0006434 & 0.0099881 & 0.0044532 & -0.003738 & 0.0113707 \\
\hline & 3.21 & 0.15 & 3.07 & 1.48 & -1.3 & 2.79 \\
\hline time effects & yes & yes & yes & yes & yes & yes \\
\hline
\end{tabular}

\section{Appendix D: Other Robustness Checks}

Table D.1

Symmetrically Normalized Instrumental Variable Estimates of Reduced Form Models

\begin{tabular}{|c|c|c|c|c|c|c|c|c|}
\hline & \multicolumn{2}{|c|}{ Log Wealth } & & \multicolumn{2}{|c|}{ Husband's Health } & & \multicolumn{2}{|c|}{ Wife's Health } \\
\hline & Estimate & t-value & & Estimate & t-value & & Estimate & t-value \\
\hline wealth $\mathrm{t}-1$ & 0.139 & 1.650 & hlt $\mathrm{m} \mathrm{t}^{-1}$ & 0.599 & 12.500 & hlt f t -1 & 0.582 & 13.200 \\
\hline wealth $\mathrm{t}-2$ & -0.042 & -1.260 & hlt $\mathrm{m} \mathrm{t}^{-2}$ & 0.261 & 14.300 & hlt $\mathrm{ft}-2$ & 0.241 & 12.100 \\
\hline wealth $\mathrm{t}-1 \times \mathrm{t}$ & -0.667 & -4.110 & hlt $\mathrm{m} \mathrm{t}^{-}-3$ & 0.096 & 4.510 & hlt f t -3 & 0.083 & 3.830 \\
\hline
\end{tabular}




\begin{tabular}{|c|c|c|c|c|c|c|c|c|}
\hline & \multicolumn{2}{|c|}{ Log Wealth } & & \multicolumn{2}{|c|}{ Husband's Health } & & \multicolumn{2}{|c|}{ Wife's Health } \\
\hline & Estimate & t-value & & Estimate & t-value & & Estimate & t-value \\
\hline hlt $\mathrm{m} \mathrm{t}^{-1}$ & -0.278 & -3.130 & hlt $\mathrm{m} \mathrm{t}^{-1}-1 \times \mathrm{t}$ & -0.004 & -0.400 & hlt $\mathrm{ft}-1 \times \mathrm{t}$ & 0.009 & 0.785 \\
\hline hlt $\mathrm{m} \mathrm{t}-2$ & -0.348 & -2.040 & wealth $\mathrm{t}-1$ & -0.002 & -0.397 & wealth $\mathrm{t}-1$ & -0.005 & -1.610 \\
\hline hlt $\mathrm{m} \mathrm{t}^{-1} \times \mathrm{t}$ & -0.012 & -0.148 & wealth $\mathrm{t}-2$ & 0.032 & 0.824 & wealth $t-2$ & 0.016 & 0.405 \\
\hline hlt $\mathrm{ft}-1$ & -0.056 & -1.450 & wealth $\mathrm{t}-1 \times \mathrm{t}$ & -0.008 & -0.495 & wealth $\mathrm{t}-1 \times \mathrm{t}$ & -0.004 & -0.258 \\
\hline hlt $\mathrm{ft}-2$ & 0.088 & 2.470 & hlt $\mathrm{ft}-1$ & 0.001 & 0.254 & hlt $\mathrm{m} \mathrm{t}-1$ & -0.002 & -0.681 \\
\hline \multirow[t]{2}{*}{ hlt $\mathrm{ft}-1 \times \mathrm{t}$} & -0.009 & -0.246 & hlt f t -2 & -0.004 & -0.404 & hlt $\mathrm{m} \mathrm{t}-2$ & -0.002 & -0.196 \\
\hline & & & hlt $\mathrm{ft}-1 \times \mathrm{t}$ & -0.004 & -0.384 & hlt $\mathrm{m} \mathrm{t}^{-1} \times \mathrm{t}$ & -0.002 & -0.24 \\
\hline \multicolumn{3}{|c|}{ Causality Tests (p-value) } & \multicolumn{2}{|c|}{ Causality Tests (p-value) } & & \multicolumn{2}{|c|}{ Causality Tests (p-value) } & \\
\hline Hlt m & $<0.001$ & & wealth & 0.948 & & wealth & 0.204 & \\
\hline Hlt f & 0.002 & & Hlt f & 0.553 & & Hlt $\mathrm{f}$ & 0.932 & \\
\hline
\end{tabular}

Notes: Symmetrically Normalized two-step GMM estimates along with t-values.

\section{TableD.2}

Reduced Form Models with Hyperbolic Transformation of Wealth

\begin{tabular}{|c|c|c|c|c|c|c|c|c|}
\hline & \multicolumn{2}{|c|}{ Log Wealth } & \multicolumn{4}{|c|}{ Husband's Health } & \multicolumn{2}{|c|}{ Wife's Health } \\
\hline & Estimate & t-value & & Estimate & t-value & & Estimate & t-value \\
\hline wealth $\mathrm{t}-1$ & 0.478 & 18.670 & hlt $\mathrm{m} \mathrm{t}-1$ & 0.586 & 11.950 & hlt $\mathrm{f} \mathrm{t}-1$ & 0.585 & 13.400 \\
\hline wealth $\mathrm{t}-2$ & 0.205 & 10.550 & hlt $\mathrm{m} \mathrm{t}-2$ & 0.278 & 11.640 & hlt $\mathrm{f} \mathrm{t}-2$ & 0.257 & 12.920 \\
\hline wealth $\mathrm{t}-1 \times \mathrm{t}$ & 0.000 & -0.080 & hlt $\mathrm{m} \mathrm{t}-3$ & 0.105 & 4.460 & hlt $\mathrm{ft}-3$ & 0.082 & 3.740 \\
\hline hlt $\mathrm{m} \mathrm{t}^{-1}$ & -0.013 & -3.360 & hlt $\mathrm{m} \mathrm{t}^{-1} \times \mathrm{t}$ & 0.006 & 0.550 & hlt f t $-1 \times \mathrm{t}$ & 0.000 & 0.020 \\
\hline hlt $\mathrm{m} \mathrm{t}-2$ & -0.012 & -5.090 & wealth $\mathrm{t}-1$ & 0.045 & 1.220 & wealth $\mathrm{t}-1$ & 0.027 & 0.710 \\
\hline hlt $\mathrm{m} \mathrm{t}^{-1} \times \mathrm{t}$ & 0.002 & 1.720 & wealth $\mathrm{t}-2$ & -0.005 & -0.270 & wealth $\mathrm{t}-2$ & 0.003 & 0.190 \\
\hline hlt $\mathrm{ft}-1$ & -0.005 & -1.490 & wealth $\mathrm{t}-1 \times \mathrm{t}$ & -0.010 & -1.180 & wealth $\mathrm{t}-1 \times \mathrm{t}$ & -0.004 & -0.430 \\
\hline hlt $\mathrm{ft}-2$ & -0.001 & -0.330 & hlt $\mathrm{ft}-1$ & -0.231 & -1.300 & hlt $\mathrm{m} \mathrm{t}-1$ & 0.106 & 0.660 \\
\hline \multirow[t]{2}{*}{ hlt $\mathrm{f} \mathrm{t}-1 \times \mathrm{t}$} & -0.002 & -1.940 & hlt $\mathrm{f} \mathrm{t}-2$ & -0.098 & -1.050 & hlt $\mathrm{m} \mathrm{t}-2$ & -0.095 & -1.430 \\
\hline & & & hlt f t $-1 \times \mathrm{t}$ & 0.004 & 0.110 & hlt $\mathrm{m} \mathrm{t}^{-1} \times \mathrm{t}$ & -0.038 & -1.02 \\
\hline \multicolumn{3}{|c|}{ Causality Tests (p-value) } & \multicolumn{2}{|c|}{ Causality Tests (p-value) } & \multicolumn{4}{|c|}{ Causality Tests (p-value) } \\
\hline Hlt m & $<0.001$ & & wealth & 0.131 & & wealth & 0.301 & \\
\hline Hlt $\mathrm{f}$ & $<0.001$ & & Hlt f & 0.647 & & Hlt f & 0.721 & \\
\hline
\end{tabular}

Notes: Two-step GMM estimates using hyperbolic transformation of wealth.

Table D.3

Difference between Balanced and Unbalanced Panel Reduced Form Estimates and Tests for Attrition

\begin{tabular}{|c|c|c|c|c|c|c|c|c|}
\hline & \multicolumn{2}{|c|}{ Log Wealth } & & \multicolumn{2}{|c|}{ Husband's Health } & & \multicolumn{2}{|c|}{ Wife's Health } \\
\hline & Difference & std.error & & Difference & std.error & & Difference & std.error \\
\hline wealth $\mathrm{t}-1$ & $-0,023$ & 0,031 & hlt $\mathrm{m} \mathrm{t}^{-1}$ & $-0,007$ & 0,028 & hlt $\mathrm{ft}-1$ & $-0,031$ & 0,024 \\
\hline wealth $\mathrm{t}-2$ & 0,038 & 0,019 & hlt $\mathrm{m} \mathrm{t}-2$ & $-0,013$ & 0,011 & hlt $\mathrm{f} \mathrm{t}-2$ & $-0,007$ & 0,009 \\
\hline $\begin{array}{l}\text { wealth } \mathrm{t}-1 \\
\times \mathrm{t}\end{array}$ & 0,017 & 0,013 & hlt $\mathrm{m} \mathrm{t}^{-3}$ & $-0,014$ & 0,012 & hlt $f \mathrm{t}-3$ & $-0,003$ & 0,010 \\
\hline
\end{tabular}

J Health Econ. Author manuscript; available in PMC 2010 May 11. 


\begin{tabular}{|c|c|c|c|c|c|c|c|c|}
\hline & \multicolumn{2}{|c|}{ Log Wealth } & & \multicolumn{2}{|c|}{ Husband's Health } & & \multicolumn{2}{|c|}{ Wife's Health } \\
\hline & Difference & std.error & & Difference & std.error & & Difference & std.error \\
\hline hlt $\mathrm{m} \mathrm{t}^{-1}$ & 0,258 & 0,101 & ${ }_{\mathrm{t}}^{\mathrm{h}} \mathrm{mt} \mathrm{t}-1 \times$ & $-0,007$ & 0,006 & hlt $f \mathrm{t}-1 \times \mathrm{t}$ & 0,001 & 0,005 \\
\hline hlt $\mathrm{m} \mathrm{t}-2$ & 0,044 & 0,053 & wealth $\mathrm{t}-1$ & $-0,037$ & 0,017 & wealth $\mathrm{t}-1$ & $-0,039$ & 0,018 \\
\hline $\mathrm{h}_{\mathrm{t}} \mathrm{mlt} \mathrm{m}^{-1} \times$ & $-0,050$ & 0,019 & wealth $\mathrm{t}-2$ & $-0,004$ & 0,008 & wealth $\mathrm{t}-2$ & $-0,004$ & 0,007 \\
\hline hlt $\mathrm{ft}-1$ & 0,090 & 0,108 & $\begin{array}{l}\text { wealth } \mathrm{t}-1 \\
\times \mathrm{t}\end{array}$ & 0,009 & 0,004 & $\begin{array}{l}\text { wealth } t-1 \\
\times \mathrm{t}\end{array}$ & 0,008 & 0,004 \\
\hline hlt f t -2 & 0,012 & 0,042 & hlt $\mathrm{ft}-1$ & $-0,002$ & 0,004 & hlt $\mathrm{m} \mathrm{t}-1$ & 0,002 & 0,003 \\
\hline \multirow[t]{2}{*}{ hlt f $\mathrm{t}-1 \times \mathrm{t}$} & $-0,010$ & 0,022 & hlt $\mathrm{ft}-2$ & 0,004 & 0,003 & hlt $\mathrm{m} \mathrm{t}-2$ & $-0,002$ & 0,002 \\
\hline & & & hlt f t $-1 \times \mathrm{t}$ & 0,001 & 0,002 & ${ }_{\mathrm{t}}$ hlt $\mathrm{m} \mathrm{t}-1 \times$ & $-0,001$ & 0,001 \\
\hline Chi-square & 19,74 & & Chi-square & 27,81 & & Chi-square & 12,58 & \\
\hline p-value & 0,013 & & p-value & 0,0019 & & & 0,248 & \\
\hline
\end{tabular}

Notes: For each variable, the difference between parameter estimate from balanced and unbalanced sample is reported along with standard errors calculated from 50 boostrap replications. "Chi-squae" refers to the Nijman Verbeek (1996) test comparing all parameter estimates.

\section{Appendix E: Disaggregation}

\section{Table E.1}

Wealth Responses to Mental and Physical Health

\begin{tabular}{|c|c|c|c|c|}
\hline \multirow[b]{3}{*}{ Covariates } & \multicolumn{2}{|c|}{ Estimates } & \multicolumn{2}{|c|}{ Causality Tests } \\
\hline & Par & t-stat & test & p-value \\
\hline & & & & \\
\hline$y(t-1)$ & 0.146 & 2.66 & & \\
\hline $\mathrm{y}(\mathrm{t}-2)$ & 0.036 & 1.55 & & \\
\hline$y(t-1) \times t$ & -0.013 & -0.76 & & \\
\hline \multicolumn{5}{|c|}{ Mental Health } \\
\hline $\mathrm{hm}(\mathrm{t})$ & -0.616 & -1.42 & & \\
\hline $\mathrm{hm}(\mathrm{t}-1)$ & -0.031 & 0.13 & & \\
\hline $\mathrm{hm}(\mathrm{t}-2)$ & 0.051 & 0.41 & & \\
\hline$h m(t-1) \times t$ & 0.062 & 1.64 & 2.04 & 0.11 \\
\hline $\mathrm{hm}(\mathrm{t})$ & -1.125 & -2.95 & & \\
\hline $\mathrm{hm}(\mathrm{t}-1)$ & 0.298 & 1.55 & & \\
\hline $\mathrm{hm}(\mathrm{t}-2)$ & 0.229 & 2.33 & & \\
\hline$h m(t-1) \times t$ & 0.053 & 1.54 & 3.24 & 0.047 \\
\hline \multicolumn{5}{|c|}{ Physical Health } \\
\hline $\mathrm{hm}(\mathrm{t})$ & 0.139 & 0.91 & & \\
\hline $\mathrm{hm}(\mathrm{t}-1)$ & -0.484 & -2.81 & & \\
\hline $\mathrm{hm}(\mathrm{t}-2)$ & -0.127 & -1.27 & & \\
\hline
\end{tabular}

J Health Econ. Author manuscript; available in PMC 2010 May 11. 


\begin{tabular}{lrrrr}
\hline & \multicolumn{2}{c}{ Estimates } & \multicolumn{2}{c}{ Causality Tests } \\
& \multicolumn{1}{c}{ Par } & t-stat & test & p-value \\
\cline { 2 - 5 } $\mathrm{hm}(\mathrm{t}-1) \times \mathrm{t}$ & 0.093 & 2.9 & 3.02 & 0.033 \\
\hline $\mathrm{hm}(\mathrm{t})$ & 0.051 & 0.27 & & \\
$\mathrm{hm}(\mathrm{t}-1)$ & -0.378 & -1.93 & & \\
$\mathrm{hm}(\mathrm{t}-2)$ & -0.06 & -0.56 & & \\
$\mathrm{hm}(\mathrm{t}-1) \times \mathrm{t}$ & 0.001 & 0.04 & 4.12 & 0.003 \\
\hline $\mathrm{N}$ & 3386 & & & \\
\hline
\end{tabular}

The mental health index is composed of CESD scores and onsets of mental health conditions; the physical health index is based upon onsets of other severe and mild conditions and ADLs. Self-reported health excluded.

\section{Table E.2}

\section{Results by Health Insurance Status}

\begin{tabular}{lrr}
\hline \multirow{2}{*}{ Joint Test (p-value) } & \multicolumn{2}{c}{ Insurance Coverage } \\
& None & Both \\
\cline { 2 - 3 } Immediate mental & 0.006 & 0.437 \\
immediate physical & 0.199 & 0.62 \\
Husband & & \\
mental & $<0.001$ & 0.332 \\
physical & 0.088 & 0.652 \\
Wife & & \\
mental & 0.269 & 0.598 \\
physical & 0.055 & 0.001 \\
\cline { 2 - 3 } $\mathrm{N}$ & 417 & 867 \\
\hline
\end{tabular}

Notes: Specification of non-causality tests as in Table 5. 


\section{Table 1}

\section{Composition of Household Wealth}

\begin{tabular}{lrr}
\hline Wealth components in 1000's & $\begin{array}{r}\text { 1992 } \\
\text { median (\% with asset) }\end{array}$ & $\begin{array}{r}\text { 2002 } \\
\text { median (\% with asset) }\end{array}$ \\
\hline Liquid wealth & $38.81(74.1)$ & $80.0(47.8)$ \\
\hline IRAs & $31.57(45.1)$ & $68.24(47.2)$ \\
Stocks & $25.24(32.1)$ & $50.0(37.4)$ \\
Bonds & $12.62(6.9)$ & $35.0(8.6)$ \\
Checking/savings account & $6.56(86.2)$ & $10.0(89.1)$ \\
Certificates of deposit & $10.10(29.5)$ & $20.0(26.9)$ \\
Treasury bills/Saving bonds & & $5.0(28.2)$ \\
\hline Debt (subtracted) & $3.78(41.0)$ & $136.0(99.0)$ \\
\hline Non-liquid wealth & $103.51(97.2)$ & $130.0(92.3)$ \\
\hline Primary residence & $100.98(87.9)$ & $56.0(35.5)$ \\
Mortgage (subtracted) & $37.87(50.6)$ & $70.0(21.3)$ \\
Other real estate & $56.80(27.4)$ & $150.0(13.4)$ \\
Business assets & $88.36(15.2)$ & $15.0(95.7)$ \\
\hline Transportation/vehicles assets & $12.62(95.9)$ & $211.0(99.0)$ \\
\hline Number of households & $42.64(95.5)$ & \\
\hline
\end{tabular}

NOTES: Wealth in thousands of 2002 US dollars. Ownership rates in parentheses. Other debts or loans not shown in the table but enter negatively in the calculation of liquid wealth. Business assets not included. 


\section{Table 2}

Health of Husbands and Wives

\begin{tabular}{lcccc}
\hline Health Indicators & \multicolumn{2}{c}{ Husbands } & \multicolumn{2}{c}{ Wives } \\
\hline Mean/Fraction reporting condition & $\mathbf{1 9 9 2}$ & $\mathbf{2 0 0 2}$ & $\mathbf{1 9 9 2}$ & $\mathbf{2 0 0 2}$ \\
\hline Self-Reported Health & 2.577 & 2.754 & 2.420 & 2.594 \\
\hline Severe Condition (ever had) & 0.238 & 0.449 & 0.167 & 0.317 \\
\hline Cancer & 0.039 & 0.132 & 0.059 & 0.119 \\
Heart Condition & 0.148 & 0.286 & 0.072 & 0.153 \\
Lung Disease & 0.062 & 0.091 & 0.049 & 0.087 \\
Stroke & 0.038 & 0.075 & 0.017 & 0.045 \\
\hline Mild Condition (ever had) & 0.565 & 0.813 & 0.554 & 0.799 \\
\hline Diabetes & 0.101 & 0.208 & 0.076 & 0.138 \\
High blood pressure & 0.359 & 0.538 & 0.285 & 0.492 \\
Arthritis & 0.299 & 0.562 & 0.358 & 0.632 \\
Emotional/psychological problems & 0.044 & 0.089 & 0.082 & 0.184 \\
\hline At least one ADL & 0.045 & 0.105 & 0.034 & 0.102 \\
CESD score & 0.585 & 0.939 & 0.706 & 1.290 \\
Body-Mass Index & 27.31 & 27.98 & 26.76 & 27.82 \\
\hline Number of respondents & 4160 & 2463 & 4160 & 2463 \\
\hline
\end{tabular}

NOTES: Fractions with given conditions and means of quantitative health indicators. 1992 columns: all couples in 1992; 2002 columns: couples still in the panel in 2002. Self-reported health: scale from 1 (excellent) to 5 (poor); ADLs: limitations in performing activities of daily life; CESD scores: based upon eight questions on mental health; a higher score implies worse mental health. 


\section{Table 3}

The Health-Wealth Gradient

\begin{tabular}{lrr}
\hline & Median wealth (in 1000's) \\
\hline Husband's Health Index & $\mathbf{1 9 9 2}$ & $\mathbf{2 0 0 2}$ \\
\hline best (1st) quartile & 172 & 283 \\
2nd quartile & 144 & 208 \\
$\% \Delta$ 2nd - 1st & $-16.2 \%$ & $-26.5 \%$ \\
3rd quartile & 141 & 191 \\
$\% \Delta$ 3rd - 1st & $-18 \%$ & $-32.5 \%$ \\
worst (4th) quartile & 84 & 119 \\
$\% \Delta$ 4th - 1st & $-51.2 \%$ & $-57.9 \%$ \\
\hline Wife's Health Index & 1992 & 2002 \\
\hline best (1st) quartile & 186 & 294 \\
2nd quartile & 172 & 265 \\
$\% \Delta$ 2nd - 1st & $-7.3 \%$ & $-9.8 \%$ \\
3rd quartile & 116 & 177 \\
$\% \Delta$ 3rd - 1st & $-37.6 \%$ & $-39.8 \%$ \\
worst (4th) quartile & 82 & 106 \\
$\% \Delta 4$ th - 1st & $-55.9 \%$ & $-63.9 \%$ \\
\hline
\end{tabular}

NOTES: Median total household wealth in thousands 2002 US dollars by constructed health index quartile in 1992, and percentage difference with first quartile. 
Table 4

Dynamic Model for Household Wealth

\begin{tabular}{|c|c|c|c|c|}
\hline \multirow[b]{2}{*}{ Covariates } & \multicolumn{2}{|c|}{ Reduced form } & \multicolumn{2}{|c|}{ Structural } \\
\hline & Coefficient & t-value & Coefficient & t-value \\
\hline$y_{t-1}$ & 0.157 & 2.86 & 0.154 & 2.84 \\
\hline$y_{t-2}$ & 0.027 & 1.2 & 0.021 & 0.92 \\
\hline$y_{t-1} \times t$ & -0.022 & -1.28 & -0.021 & -1.22 \\
\hline$h_{t}^{m}$ & - & & -0.218 & -1.48 \\
\hline$h_{t-1}^{m}$ & -0.720 & -4.95 & -0.586 & -3.53 \\
\hline$h_{t-2}^{m}$ & -0.308 & -3.70 & -0.249 & -2.75 \\
\hline$h_{t-1}^{m} \times t$ & 0.109 & 3.42 & 0.112 & 3.57 \\
\hline$h_{t}^{f}$ & - & & -0.434 & -2.40 \\
\hline$h_{t-1}^{f}$ & -0.402 & -2.67 & -0.155 & -0.86 \\
\hline$h_{t-2}^{f}$ & 0.038 & 0.48 & 0.123 & 1.51 \\
\hline$h_{t-1}^{f} \times t$ & 0.020 & 0.6 & 0.022 & 0.68 \\
\hline & $\chi^{2}$ & $\mathrm{p}$-value & $\chi^{2}$ & $\mathrm{p}$-value \\
\hline Sargan p-value & 45.64 & 0.04 & 46.75 & 0.04 \\
\hline $\mathrm{AR}(2)$ test on residuals & -0.096 & 0.95 & -0.025 & 0.96 \\
\hline Causality tests (p-values) & & & & \\
\hline$h_{t-1}^{m}, t \times h_{t-1}^{m}, h_{t-2}^{m}$ & $<0.001$ & & & \\
\hline$h_{t-1}^{f}, t \times h_{t-1}^{f}, h_{t-2}^{f}$ & $<0.001$ & & & \\
\hline$h_{t}^{m}, h_{t-1}^{m}, t \times h_{t-1}^{m}, h_{t-2}^{m}$ & & & $<0.001$ & \\
\hline$h_{t}^{f}, h_{t-1}^{f}, t \times h_{t-1}^{f}, h_{t-2}^{f}$ & & & $<0.001$ & \\
\hline$h_{t}^{m}, h_{t}^{f}$ & & & 0.01 & \\
\hline $\mathrm{N}$ & 3386 & & 3386 & \\
\hline
\end{tabular}

NOTES: Two-step system GMM estimates imposing mean stationarity. 
Table 5

Dynamic Model for the Husband's Health

\begin{tabular}{|c|c|c|c|c|}
\hline \multirow[b]{2}{*}{ Covariates } & \multicolumn{2}{|c|}{ Reduced Form } & \multicolumn{2}{|c|}{ Structural } \\
\hline & Coefficient & t-value & Coefficient & t-value \\
\hline$h_{t-1}^{m}$ & 0.571 & 12.63 & 0.571 & 11.75 \\
\hline$h_{t-2}^{m}$ & 0.272 & 15.12 & 0.272 & 14.18 \\
\hline$h_{t-3}^{m}$ & 0.102 & 4.76 & 0.100 & 4.65 \\
\hline$h_{t-1}^{m} \times t$ & 0.009 & 0.85 & 0.009 & 0.82 \\
\hline$h_{t}^{f}$ & & & 0.037 & 0.78 \\
\hline$h_{t-1}^{f}$ & 0.052 & 1.45 & 0.033 & 0.74 \\
\hline$h_{t-2}^{f}$ & -0.003 & -0.21 & -0.014 & -0.7 \\
\hline$h_{t-1}^{f} \times t$ & -0.009 & -1.07 & -0.010 & -1.21 \\
\hline$y_{t}$ & & & -0.003 & -0.13 \\
\hline$y_{t-1}$ & 0.001 & 0.04 & 0.001 & 0.10 \\
\hline$y_{t-2}$ & -0.002 & -0.41 & -0.002 & -0.43 \\
\hline$y_{t-1} \times t$ & -0.001 & -0.24 & -0.001 & -0.27 \\
\hline & $\mathrm{p}$-value & & p-value & \\
\hline Sargan test & 0.585 & & 0.546 & \\
\hline Causality tests & & & & \\
\hline$h_{t-1}^{f}, t \times h_{t-1}^{f}, h_{t-2}^{f}$ & 0.41 & & & \\
\hline$y_{t-1}, t \times y_{t-1}, y_{t-2}$ & 0.71 & & & \\
\hline$h_{t}^{f}, h_{t-1}^{f}, t \times h_{t-1}^{f}, h_{t-2}^{f}$ & . & . & 0.547 & \\
\hline$y_{t} y_{t-1}, t \times y_{t-1}, y_{t-2}$ & . & . & 0.961 & \\
\hline $\mathrm{N}$ & 3051 & & 3051 & \\
\hline
\end{tabular}

NOTES: Two-step system GMM estimates imposing mean stationarity. 
Table 6

Dynamic Model for the Wife's Health

\begin{tabular}{|c|c|c|c|c|}
\hline \multirow[b]{2}{*}{ Covariates } & \multicolumn{2}{|c|}{ Reduced form } & \multicolumn{2}{|c|}{ Structural } \\
\hline & Coefficient & t-value & Coefficient & t-value \\
\hline$h_{t-1}^{f}$ & 0.574 & 13.25 & 0.570 & 13.16 \\
\hline$h_{t-2}^{f}$ & 0.254 & 13.1 & 0.253 & 13.11 \\
\hline$h_{t-3}^{f}$ & 0.080 & 3.73 & 0.082 & 3.82 \\
\hline$h_{t-1}^{f} \times t$ & 0.004 & 0.37 & 0.003 & 0.29 \\
\hline$h_{t}^{m}$ & . & . & 0.031 & 0.80 \\
\hline$h_{t-1}^{m}$ & 0.045 & 1.21 & 0.003 & 0.06 \\
\hline$h_{t-2}^{m}$ & 0.002 & 0.17 & -0.018 & -0.96 \\
\hline$h_{t-1}^{m} \times t$ & -0.007 & -0.76 & -0.004 & -0.45 \\
\hline$y_{t}$ & . & . & -0.034 & -1.33 \\
\hline$y_{t-1}$ & 0.007 & 0.73 & 0.007 & 0.61 \\
\hline$y_{t-2}$ & -0.002 & -0.54 & -0.001 & -0.21 \\
\hline$y_{t-1} \times \mathrm{t}$ & -0.001 & -0.35 & 0.001 & -0.12 \\
\hline & $\mathrm{p}$-value & & p-value & \\
\hline Sargan test & 0.412 & & 0.325 & \\
\hline Causality tests & & & & \\
\hline$h_{t-1}^{m}, t \times h_{t-1}^{m}, h_{t-2}^{m}$ & 0.551 & & & \\
\hline$y_{\mathrm{t}-1}, t \times y_{t-1}, y_{t-2}$ & 0.693 & & & \\
\hline$h_{t}^{m}, h_{t-1}^{m}, t \times h_{t-1}^{m}, h_{t-2}^{m}$ & . & & 0.552 & \\
\hline$y_{t}, y_{t-1}, t \times y_{t-1}, y_{t-2}$ & . & . & 0.988 & \\
\hline $\mathrm{N}$ & 3051 & & 3051 & \\
\hline
\end{tabular}

NOTES: Two-step system GMM estimates imposing mean stationarity. 
Table 7

\section{Covariance Structure of Individual Effects}

\begin{tabular}{lccc}
\hline covariance matrix & wealth & husband's health & wife's health \\
\hline wealth & $1.119(81.5 \%)$ & & \\
husband's health & 0.019 & $0.019(8.9 \%)$ & \\
wife's health & 0.012 & -0.003 & $0.016(6.9 \%)$ \\
\hline
\end{tabular}

NOTES: The percentages in parentheses are the percentages of the unsystematic variance accounted for by the unobserved heterogeneity terms $\eta_{i}$ in each equation. The variances and covariances are estimated using residuals from structural models in Tables 5, 6 and 7. Using observations in the balanced panel only, the covariance matrix can be constructed as follows: Denote the GMM residuals by $\widehat{u}_{i t}^{j}, j=1,2,3, i=1, \ldots, n, t=P+1(=4), \ldots$,

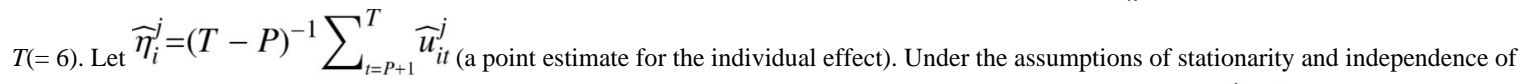
individual effects and error terms, it is easy to show that a consistent estimator (with $T$ fixed and $n \rightarrow \infty)$ for $\operatorname{Cov}\left(u_{i t}^{j}, u_{i t}^{k}\right)$ is given by $(T-P-1)^{-1}\left[(T-P) \widehat{C} o v\left(\widehat{\eta}_{i}^{j}, \widehat{\eta}_{i}^{k}\right)-\widehat{C} o v\left(\widehat{u}_{i t}^{j}, \widehat{u}_{i t}^{k}\right)\right]$, where $\hat{C} o v$ denotes the sample covariance. Similar consistent estimators can be constructed using observations that are not in the balanced panel, particularly households observed 5 consecutive times for which we have 3 ( 2 health) GMM residuals. The reported numbers are weighted averages of the covariance matrix estimates using households with 6 and 5 panel observations, weighted with the numbers of such households. 


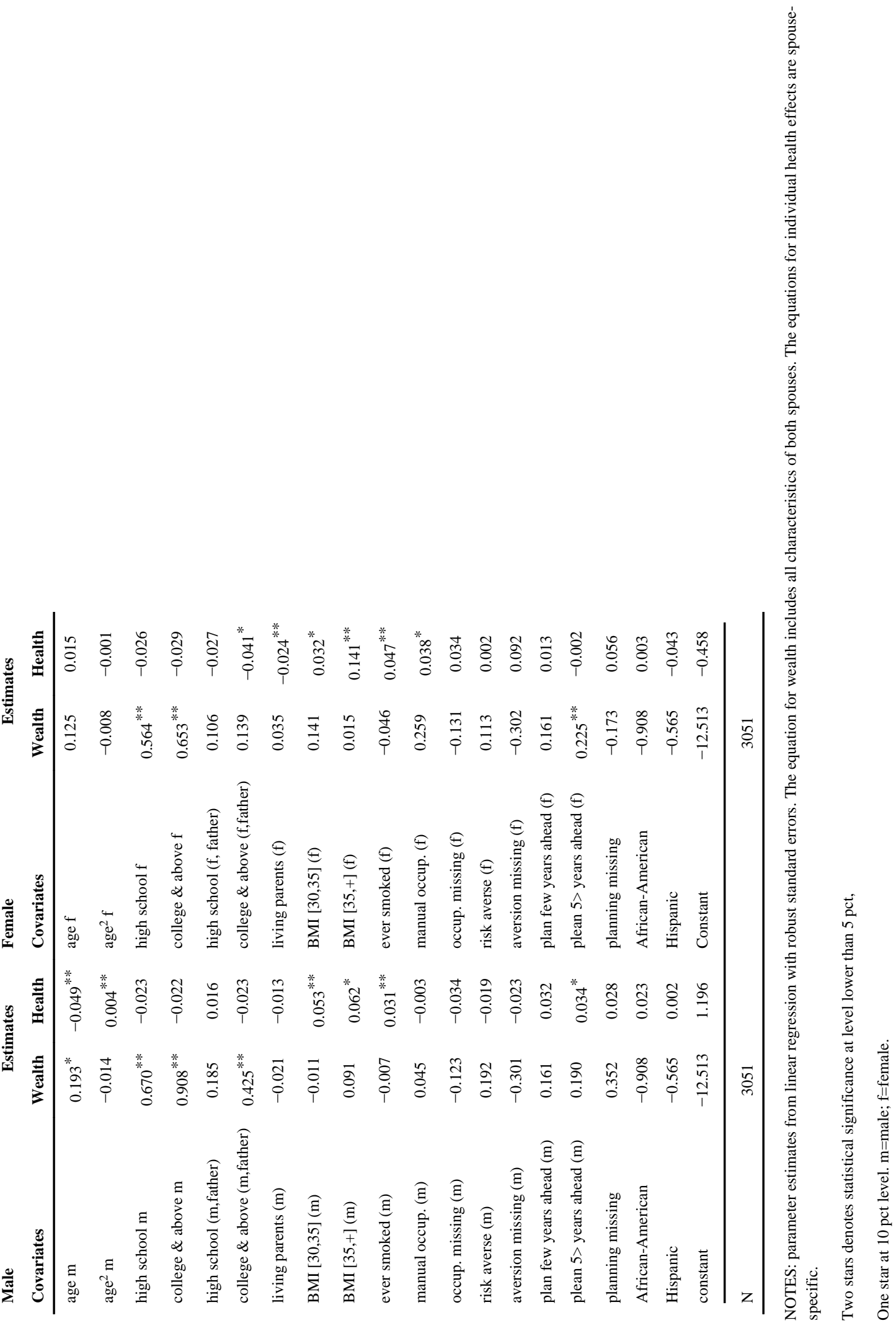


